\title{
Reduction of Borax / Agar-based Gel Residues Used to Neutralize Acidity of a Historical Manuscript with use of Different Paper Barriers: Artificial Ageing Results
}

\author{
Eman Salim, ${ }^{\text {a }}$ Mostafa Abdel-Hamied, ${ }^{\text {a }}$ Sehame Salim, ${ }^{\text {a }}$ Sheeren Gamal, ${ }^{\text {a }}$ \\ Shimaa Mohamed, ${ }^{\mathrm{a}}$ Fatma El-Zahraa Galal, ${ }^{\mathrm{a}}$ Fatma Tarek, ${ }^{\mathrm{a}}$ Rushdya Rabee Ali Hassan, ${ }^{\mathrm{a}}$ \\ Hayssam M. Ali, ${ }^{\text {b,c }}$ and Mohamed Z. M. Salem ${ }^{\text {d,* }}$
}

\begin{abstract}
Borax-agar gel has been used recently in the deacidification and other conservation processes for paper manuscripts. However, the residues of borax-agar can be damaging to the cellulose fibers. Conservators are trying to solve this problem, especially with the great success achieved by the borax / agar based gel in the acidity neutralization and improve the mechanical properties of the paper manuscripts. The current study considers whether the use of paper barriers such as Japanese gampi, linen, and rayon can reduce harmful borax-agar residues. Historical paper specimens were treated with $3 \%$ and $6 \%$ of agar poultice with different barriers such as rayon, pure linen, and Japanese gampi paper. After drying, the treated paper samples were exposed to hot-moist ageing at 80 ${ }^{\circ} \mathrm{C}$ and $65 \%$ relative humidity for $72 \mathrm{~h}$. The role of different barriers used in the reduction of residues from agar poultice and the effect of these residues on cellulose fibers were studied via some analytical techniques, such as digital optical microscopy, scanning electron microscopy, $\mathrm{pH}$, color change, and Fourier-transform infrared spectroscopy (FTIR), were used. The results showed that $3 \%$ of the agar poultice-borax with a linen barrier gave the best results with no residue left after treatment.
\end{abstract}

Keywords: Agar gel residues; Optical microscope; SEM; pH; Color change; FTIR

Contact information: a: Conservation Department, Faculty of Archaeology, Cairo University, Giza 12613, Egypt; b: Botany and Microbiology Department, College of Science, King Saud University, P.O. Box 2455, Riyadh 11451, Saudi Arabia; c: Timber Trees Research Department, Sabahia Horticulture Research Station, Horticulture Research Institute, Agriculture Research Center, Alexandria 21526, Egypt; d: Forestry and Wood Technology Department, Faculty of Agriculture (EL-Shatby), Alexandria University, Alexandria 21545, Egypt; *Corresponding author: zidan_forest@yahoo.com

\section{INTRODUCTION}

Many libraries, museums, and stores contain paper manuscripts that are suffering from deterioration aspects, such as acidity and dirt, and such problems call for deacidification and cleaning (Zou et al. 1996; Warda et al. 2007; Baglioni et al. 2009; Domingues et al. 2013; El-Feky et al. 2014). The acidity plays an important role in degradation of ancient manuscripts (Kolar et al. 1997, 2003, 2006). In principle, paper is formed with a network structure involving cellulose and non-cellulose (hemicelluloses and lignin) components. These materials are held together with hydrogen bonds; therefore, the mechanical properties of different paper samples are substantially influenced by the individual characteristics of cellulose fibers, by the nature, concentration and chemical properties of fillers and additives, as well as by the network structure of the paper (Hinterstoisser and Salmén 2000). 
When cellulosic materials are exposed to elevated temperatures, changes can occur in their chemical structures that affect its performance. The changes in chemical structure may be manifested only as reduced strength, and water content and of course change of $\mathrm{pH}$ (Hassan 2016).

Furthermore, the acidity may be due to the use of iron ink in writing. Such ink which contains mainly sulfur compounds (sulfate ferric) with tannic and gallic acids, and sulfuric acid $\left(\mathrm{H}_{2} \mathrm{SO}_{4}\right)$ is formed in the presence of moisture and dust. This leads to formations of burns beneath it in some cases. The acidity plays an important role in the damage and degradation of historical paper and its holdings (Badea et al. 2012; Elamin et al. 2018a,b). With the passage of time, the paper gradually becomes more and more brittle which leads finally to a complete disintegration after several hundred years of storage. Two processes have explained the degradation of paper; metal-catalyzed oxidation and acidcatalyzed hydrolysis of cellulose. Both phenomena can occur simultaneously or independently from each other; the final stage of these reactions is the high acidity and decomposition of the paper (Baty et al. 2010; Hubbe et al. 2017).

A recent study showed that impregnated interleaving papers with the ethanolic extracts produced from Lemna gibba and Eichhornia crassipes effectively neutralized the acidity of decayed paper after $7 \mathrm{~d}$ from the treatment with evidently chelated transition metals (Mohamed et al. 2019). Furthermore, the daylight and the artificial light interior, especially the more energy-rich component - near ultraviolet radiation (UVA) cause gradual degradation of paper, fabrics and other organic based materials (Olabi 2017; Brunetti et al. 2019). Many authors associate the yellowing of bleached pulp and paper with oxidation of cellulose and subsequent increasing of carbonyl group content. This is a result of acid hydrolysis - the degradation of macromolecules of cellulose, hemicelluloses, and lignin, with the creation of increased share of low molecular fractions with high presence of carbonyl and carboxyl groups, which may be the cause of increased paper acidity (Feller 1994; Fan et al. 2011). Several processes have been introduced to effectively neutrals the acidity in paper and arrest its deterioration action (Agrawal and Barkeshli 1997).

Some researchers have studied the effects of various type of deacidification on stability of cellulose, where none of the methods gave homogeneous distribution of active compounds in the paper. For example, a natural dye (in dyed paper) like turmeric is not stable and will change color during the deacidification process, and it was found that the chemical composition of the paper components is affected by organic solvents commonly used in deacidification of archaeological paper; this is especially the case for toluene and ethyl alcohol, which accelerated oxidation and hydrolysis of paper samples (Wahba et al. 2020).

The sol-gel process is one of the most important approaches used in the conservation of historical paper manuscripts, where it has some advantages, such as easy and securely controlled, which makes it useful in applications of paper preservation. Additionally, the gel has a multi-function structure. Most associated studies within the last 15 years have tended to use gel in the treatment of paper manuscripts in cleaning, to extract salt from some materials (Ellis and Ellis 1997; Campbell et al. 2011; Hassan 2015; Hassan and Mohamed 2017, 2018; Hamed and Hassan 2019).

Recently, agar gel has been used in deacidification and other conservation processes of paper manuscripts (Hughes and Sullivan 2016). The material is regarded by some today as one of the most innovative for use in conservation. Agar, a polysaccharide complex derived from marine seaweeds, is indeed the oldest known gelling agent, used 
over the centuries in numerous fields, mainly as a food additive (Jönsson et al. 2020). Agar is composed of two different polymers, both made from the simple sugar galactose: agarose, a linear-chain, neutral and high-molecular weight polymer; and agaropectin, the same basic structure containing methyl, sulphate, and pyruvate substituent groups. Perhaps one of the most important adverse effects of agar on paper is to increase the rate of bacterial activity (Ishida et al. 2003; Bae et al. 2004).

Polymeric gel systems can be prepared by means of reversible chemical crosslinks between borate ions (from borax salt $\left[\mathrm{Na}_{2} \mathrm{~B}_{4} \mathrm{O}_{7} \cdot 10 \mathrm{H}_{2} \mathrm{O}\right]$ ) and partially hydrolyzed agar to obtain agar-borate gels with a highly viscous liquids that can conform to multi-dimensional and complex surfaces, and as elastic solids (Angelova et al. 2015; Riedo et al. 2015). Responsive agar - borax gels offer several advantages over nonresponsive physical solvent gels for conservation applications. These gels are both effective as cleaning tools and are easily removable from the painted surface once they have carried out their function because they are converted rapidly to free-flowing liquids. Thus, by modulating the chemical and/or conformational properties of the gelator, it is possible to apply a gel and, after the activation of a chemical or physical switch, induce a physical gel/sol transition (Sacco et al. 2018).

Removing the sol from the surface of a work of art minimizes mechanical action over the surface of the work of art and diminishes the possibility of surface damage (Khandekar 2000; Alam et al. 2012). Furthermore, such cleaning generally requires no aqueous clearance procedure. In some instances, the soiling material dislodged from the surface is drawn into the gel particles, or simply on to the surface of the gel membrane. In other instances, particularly when a film-forming material gives the soil coherence and some character of an actual film, application of the rigid Agar gel simply swells the soil layer, which can then be removed by the gentle action of a dry cotton swab. Within this working strategy, the use of a grated rigid agar gel leads to further improvements: more gentle and uniform action, without any problems due to adhesiveness (Cremonesi 2016). Nevertheless, the researchers did not pay attention to the borax-agar residues that could cause damage to the paper structure, so the present study is unique in terms of its study to reduce the borax material residues in the gel agar systems through the usage of various barriers. A further goal was to assess the extent of the efficiency of borax/agar based gel in deacidification and the amount of borax harmful residues after application. Several studies have tried to improve the use of gel in cleaning processes with different methods, either mechanical or chemical cleaning, which left uncontrolled residues. Some previous studies revealed that the use of agar poultice is better than the use of chemicals in the treatment processes, and the remains of which are lower compared with the remains of solutions on cellulose fibers. The ageing is one of the important steps that has an active role in the evaluation of treatment after its ageing for long-term (Devanathan 2012).

This study aims to evaluate the use of different barriers as a means to reduce the residues of borax-agar on historical manuscripts and the effect of those residues on cellulose fibers under artificial ageing. Therefore, this work is complementary to the actual evaluation of the efficacy of the agar and borax material in the deacidification of paper manuscripts. The study was undertaken on historical samples from special groups, which gives more accurate and realistic results for the nature of manuscripts. In addition, it provides a number of solutions for the residues within the paper structure. 


\section{EXPERIMENTAL}

\section{Historical Paper Samples}

A historical paper manuscript sheet (Fig. 1) was used in the experimental aspect in the current study. It dates back to $1887 \mathrm{AD}$, and the manuscript was obtained from special collections, Cairo, Egypt. The authors used a microscopic examination to identify the type of paper. The scanning electronic microscope (FEI Quanta 200 ESEM FEG; FEI Company, Seto, Japan) examination showed that the manuscript paper was probably made from flax (Fig. 2).

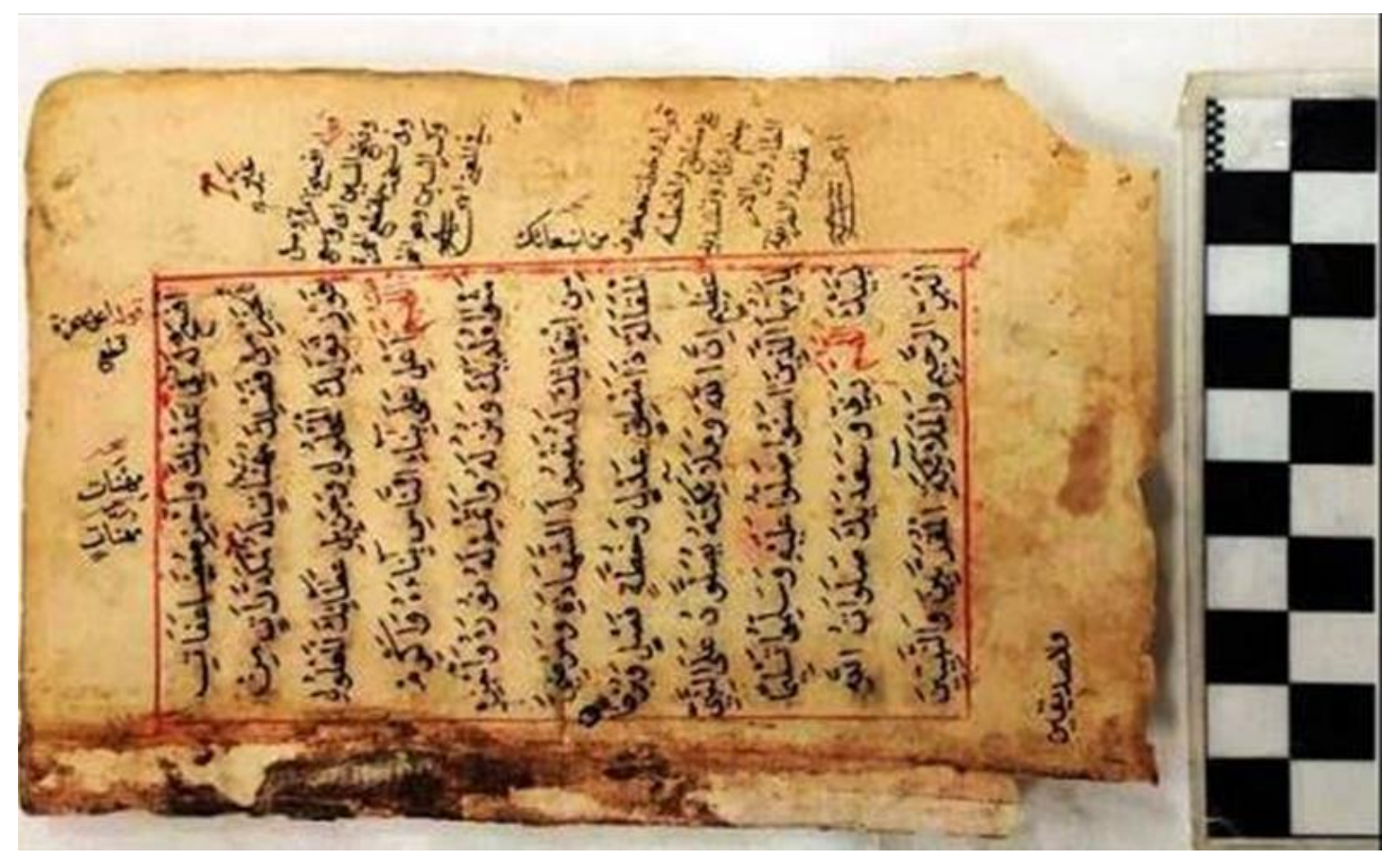

Fig. 1. The historical paper manuscript with leather bookbinding 


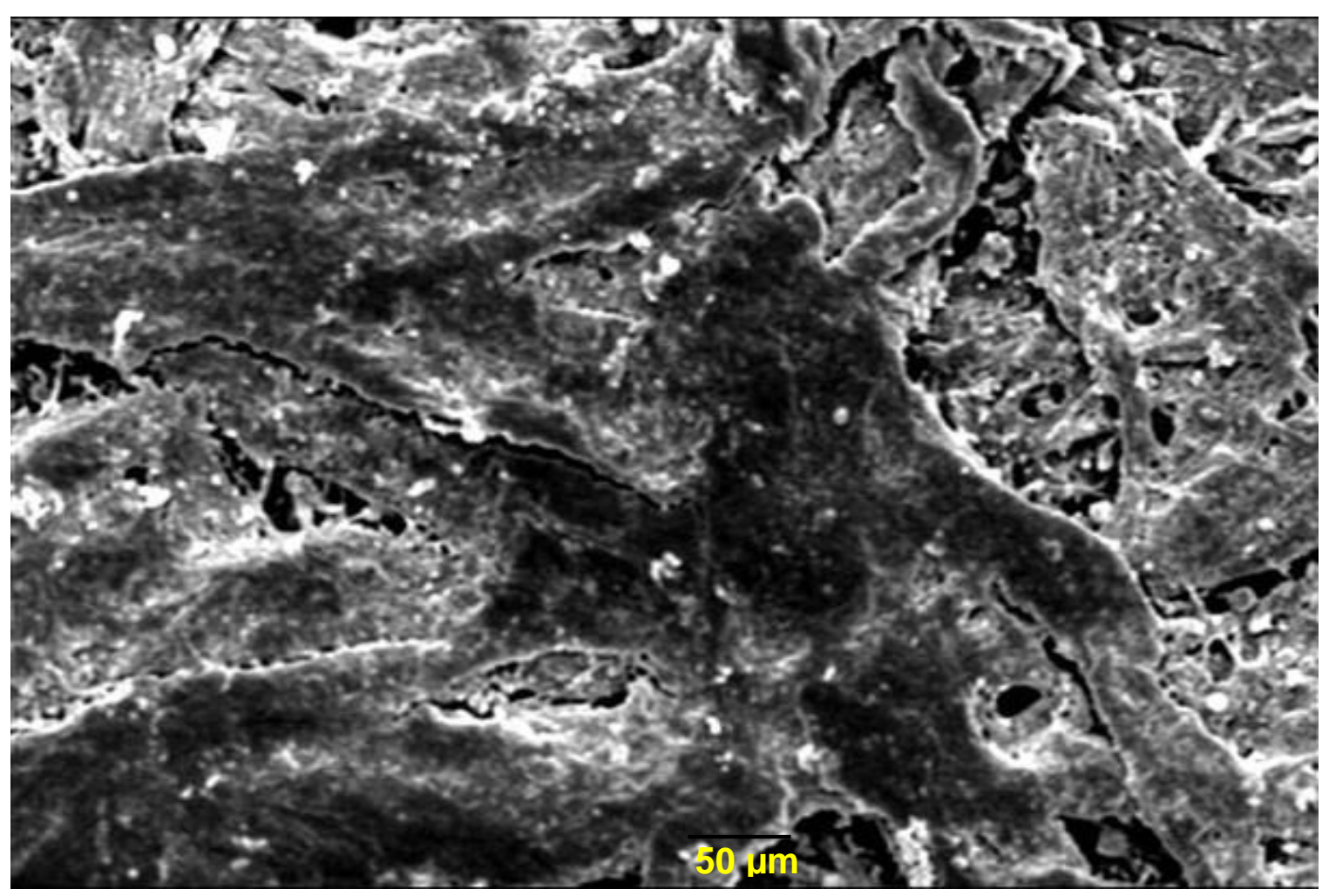

Fig. 2. The SEM image of historical paper before treatment with agar gel

The fiber was inherently characterized as flax based of its strength and durability with a low percentage of lignin, ranging from 2 to $5 \%$, as well as the cylindrical compartmentalized partitions with walls incidental thick canal central narrowness.

\section{Preparation of Agarose Poultice}

Two concentrations (3\% and 6\%) of agarose were prepared (Granan et al. 1987; Kelly 1987; Zarubica et al. 2015). Briefly, water was boiled at $100{ }^{\circ} \mathrm{C}$, and then agar with borax (Kraemer Company, Bremen, Germany) were added gradually under stirring. After completely solving the agar (Fig. 3a), the beaker was put inside an oven for $1 \mathrm{~min}$. Then, the prepared material was poured into a glass mold with $1 \mathrm{~cm}$ thickness. The poured material was left for $1.5 \mathrm{~h}$ to reach the jelly state (texture) (Fig. 3b). 

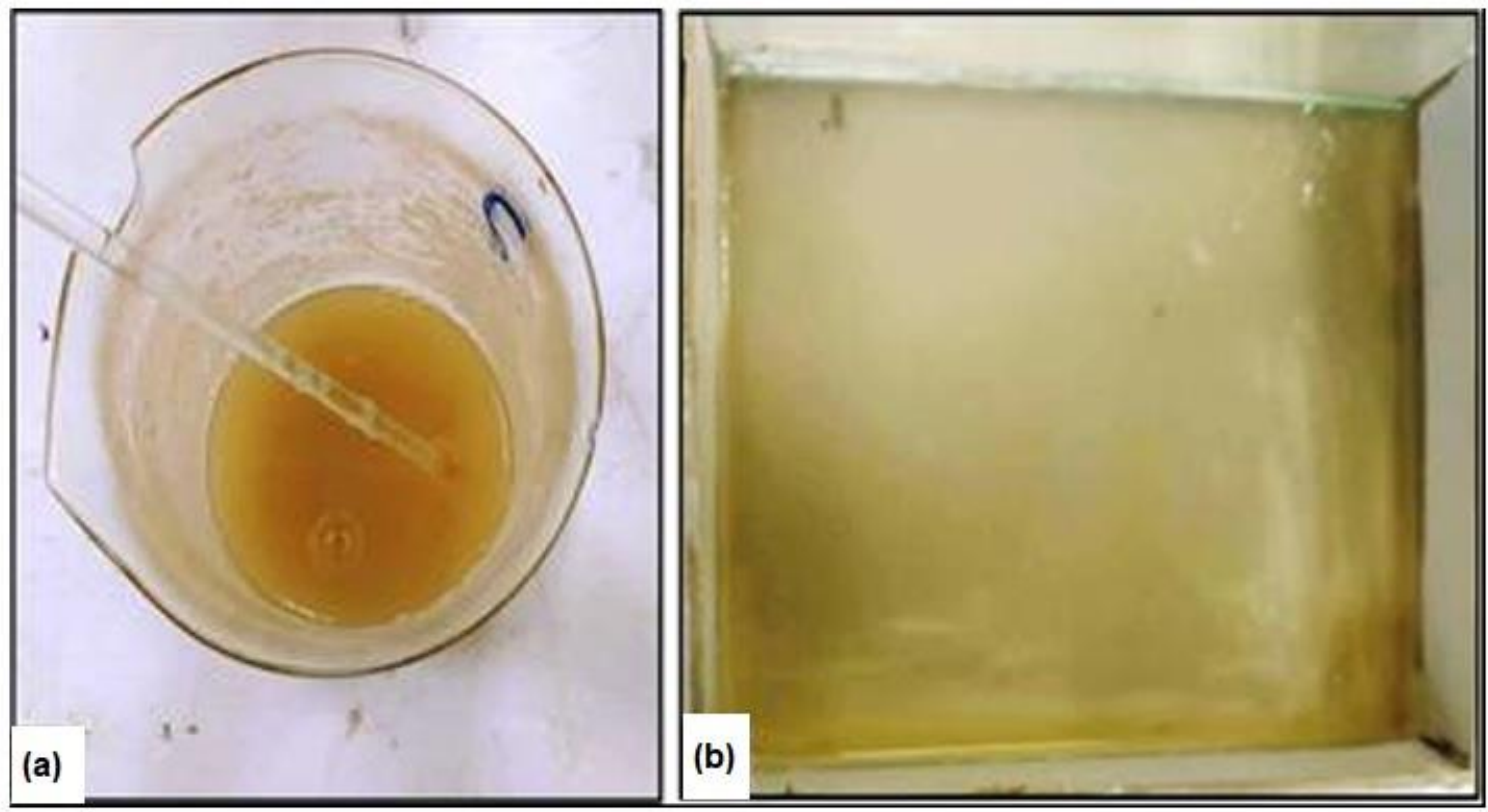

Fig. 3. Preparation steps of agar poultice: (a) Agarose after completely solving; (b) Agarose poured inside glass mold

\section{Application of Agarose with Different Barriers}

After reaching to the jelly state, the agarose was cut into small samples. Then, different barriers were put onto historical paper samples before treatment processes, such as pure linen, rayon, and Japanese gampi paper (Fig. 4). These were used to evaluate how well these barriers will succeed in reducing poultices gel residue. Agarose was put on the paper samples with different barriers and left for $1.5 \mathrm{~h}$. After the $1.5 \mathrm{~h}$, the agarose with different barriers were removed from the samples and left to completely dry at room temperature.

\section{Accelerated Moist-heat Ageing}

The treated and untreated historical samples were exposed to a moist-heat treatment at $80{ }^{\circ} \mathrm{C}$ and $65 \%$ relative humidity for $72 \mathrm{~h}$, as per ISO 5630-4 (1986). The oven used in this ageing process was from the National Institute for Standards, Giza, Egypt.

\section{Analytical Techniques}

Digital microscope

A portable USB digital microscope (model PZ01; Shenzhen Super Eyes Co., Ltd., Guangdong, China) was used to investigate the surface of the experimental samples. 

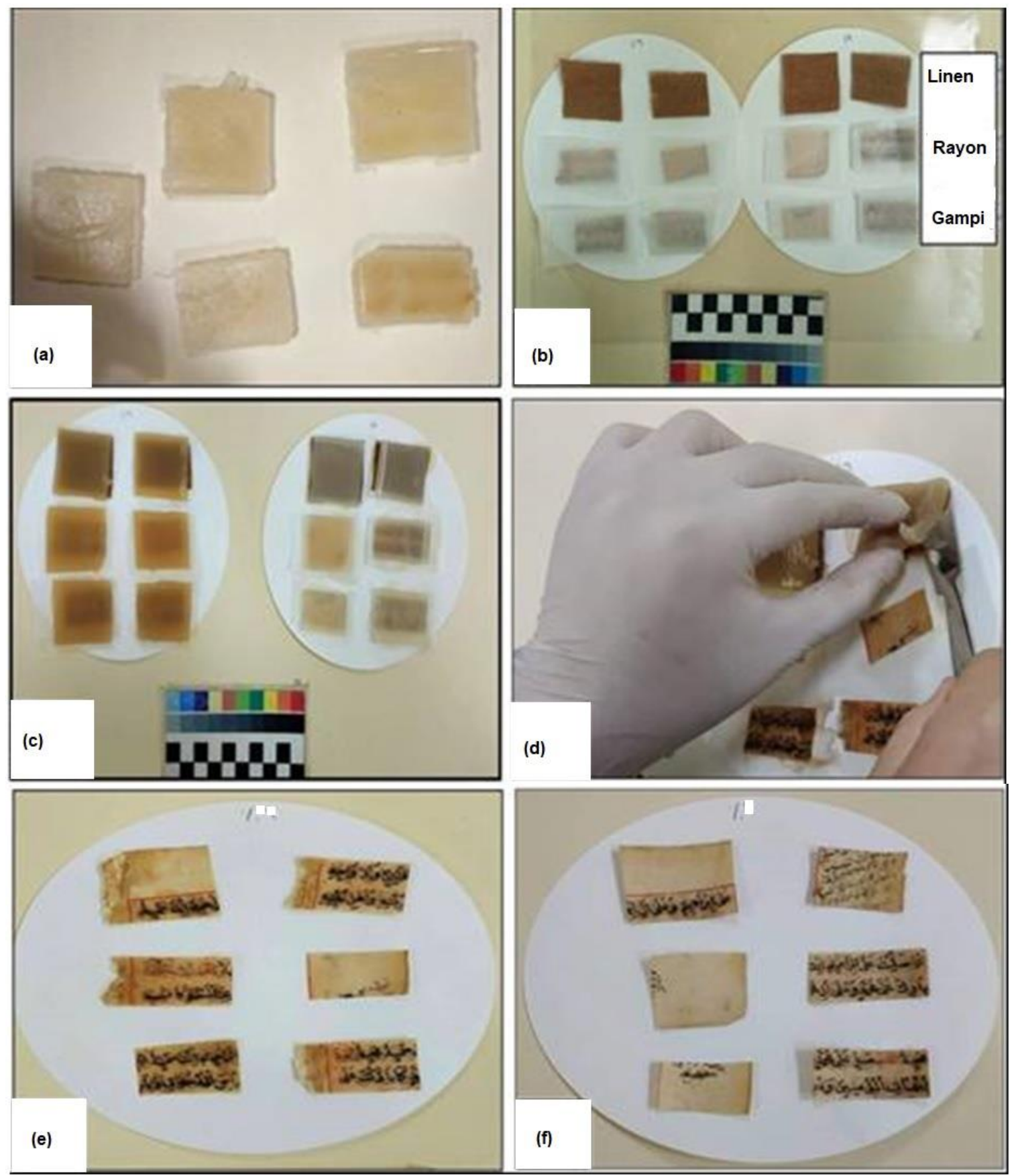

Fig. 4. Application steps of agar poultice on historical paper: (a) Agar after drying was cut into small samples; (b) Putting barriers on historical samples; (c) Putting agar poultice above barriers; (d) Removing poultices and barriers; (e) The paper samples after removing poultices; (f) Paper samples after completely drying

\section{Color change measurements}

The changes in the color parameters $L, a$, and $b$ were measured with a Hunter lab colorimeter (HunterLab Labscan 600 spectrocolorimeter, version 3.0; Hunter Associates Laboratory Inc., Reston, VA, USA); $L$ index refers to black-to-white color, $a$ index refers to green-to-red color, and $b$ index refers blue-to-yellow color. 
The overall change in color indices due to ageing was expressed as $\Delta E$ according to the following formula (George 1995; Ali et al. 2018; Salem et al. 2019),

$$
\Delta E=\sqrt{(\Delta L)^{2}+(\Delta a)^{2}+(\Delta b)^{2}}
$$

where $=(\Delta L)^{2},(\Delta a)^{2}$, and $(\Delta b)^{2}$ are the differences between the values of the color indices before and after ageing.

\section{Scanning electron microscope (SEM)}

A scanning electron microscope Zeiss LEO1550 (SEM LEO 1550VP; Carl Zeiss AG, Oberkochen, Germany), equipped with an Edwards Scan Coat K550X sputter coater (Gordon Brothers, Boston, MA, USA) at Asyut University was used for investigation the morphology of the untreated and treated inked paper samples with agar.

\section{Measuring of $\mathrm{pH}$}

Measurement of $\mathrm{pH}$ was performed on samples according to TAPPI 509 om-02 (2002) (cold extraction, $1 \mathrm{~g}$ of sample per $70 \mathrm{~mL}$ of water) (Kočar et al. 2004; Standard ISO 6588-1 2005). The $\mathrm{pH}$ values were measured by using a $\mathrm{pH}$ meter (Misura line ML 1010 pH meter; Servicios de Análisis Químico Aquater Limitada, La Florida Santiago, Romania), between $\mathrm{pH} 4.01$ and 7.01 at $20^{\circ} \mathrm{C}$.

\section{FTIR spectra}

The FTIR was used to monitor the chemical characterization and the changes that occurred in the paper due to treatment of agarose poultice using different tissue carriers. The samples were analyzed with an FTIR spectrometer (Model 6100; Jasco, Tokyo, Japan). The spectra were obtained in the transmission mode with a TGS detector using the $\mathrm{KBr}$ method and represent $(2 \mathrm{~mm} / \mathrm{s})$ co-added scans in the spectral region ranging from 4000 to $400 \mathrm{~cm}^{-1}$, with a resolution of $4 \mathrm{~cm}^{-1}$.

All samples were given codes as shown in Table 1. : the conditioning atmosphere for application and analysis was $50.0 \% \pm 2.0 \% \mathrm{RH} \pm 1.0^{\circ} \mathrm{C}$ according to TAPPI $402 \mathrm{sp}-$ 08 (2013).

Table 1. Sample's Code for FTIR Measurements

\begin{tabular}{|c|c|}
\hline Materials & Code \\
\hline Agarose & $A$ \\
\hline Concentration & $3 \%$ and $6 \%$ \\
\hline \multicolumn{2}{|c|}{ Barriers } \\
\hline Japanese gampi Paper & $G$ \\
\hline Pure Linen & $\mathrm{L}$ \\
\hline Rayon & $\mathrm{R}$ \\
\hline Before Ageing & 0 \\
\hline After Ageing & 1 \\
\hline
\end{tabular}




\section{RESULTS AND DISCUSSION}

\section{Optical Microscope}

The optical microscope images (zoom x40) of the untreated and treated samples with agarose (3\%) are shown in Fig. 5. Some impurities and black stains were noted on the untreated sample after accelerating ageing, which confirmed impact of artificial ageing in oxidation of cellulose components. In the treated sample with agarose (3\%) with Japanese gampi barrier, it can be easily noticed that the fibres became more flexible than untreated.
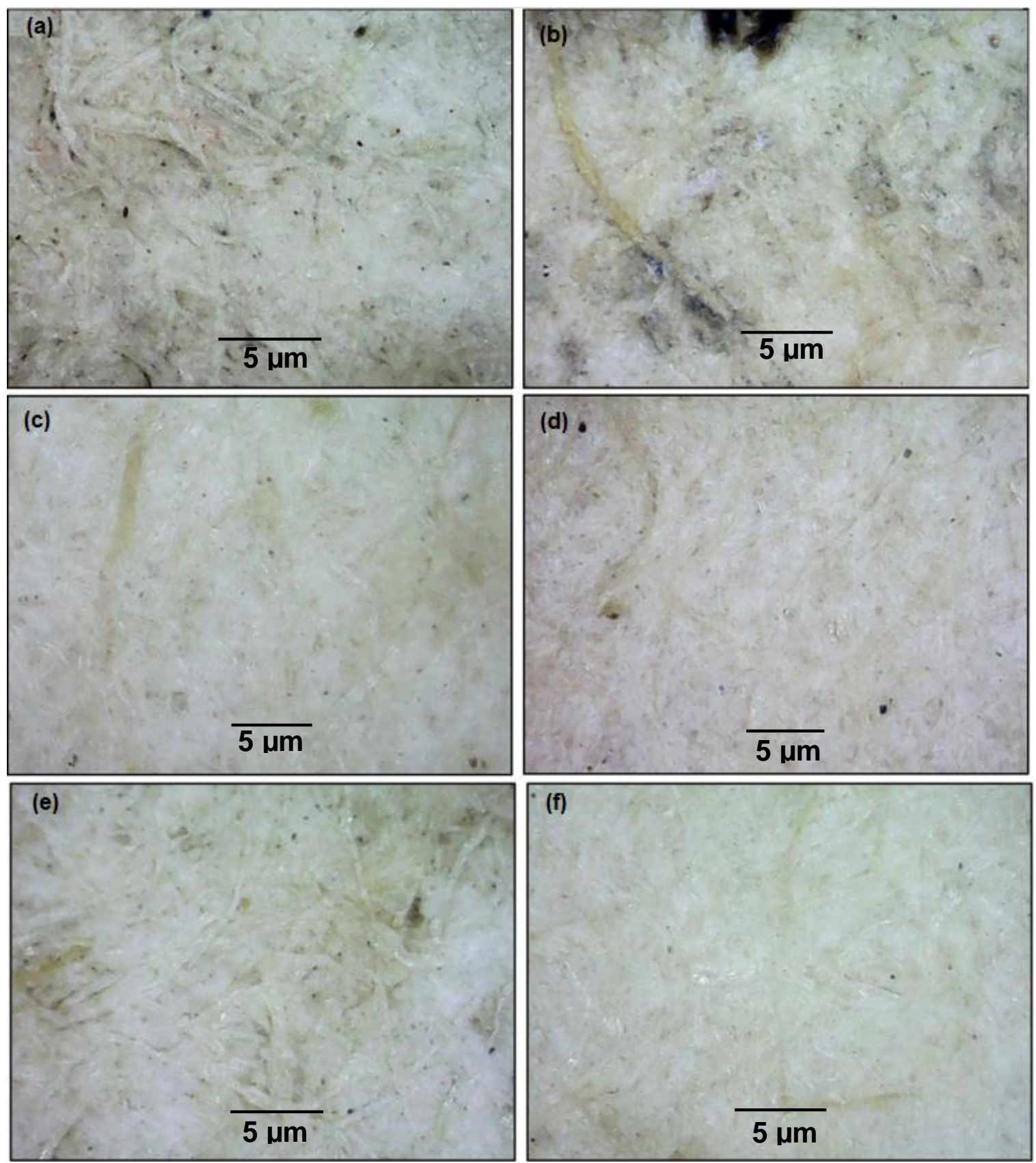

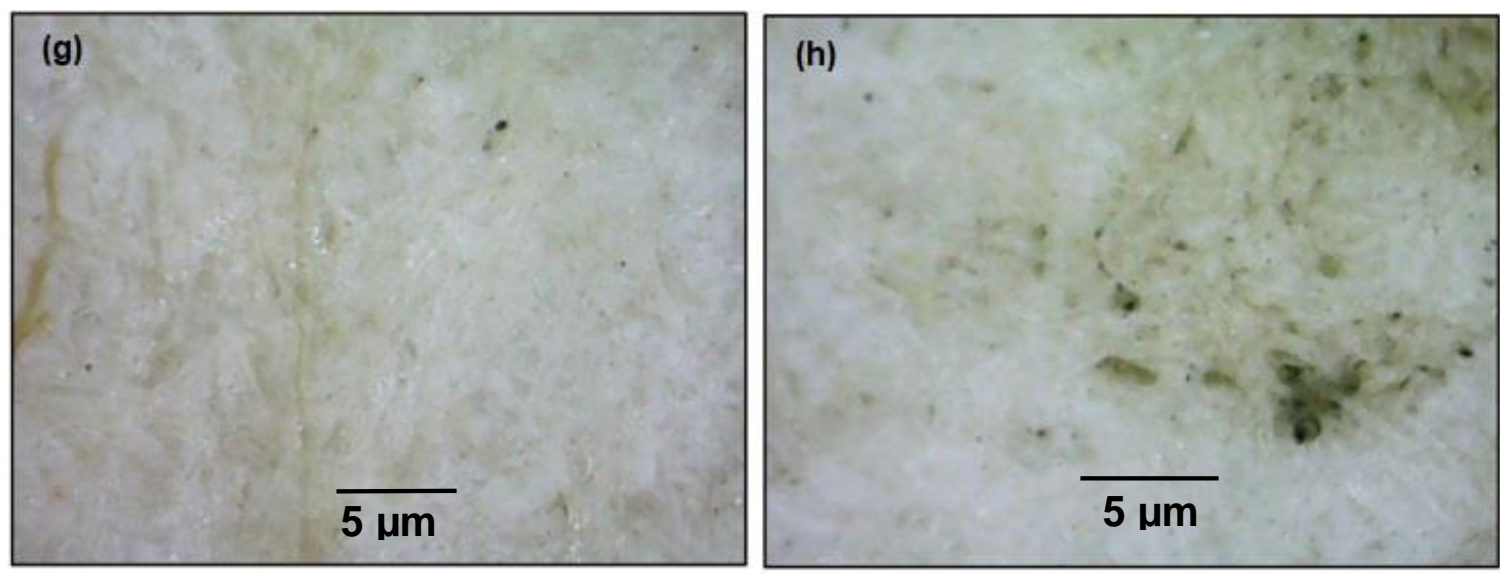

Fig. 5 (g-h). Images of optical micrographs (zoom $\times 40$ ) for treated paper samples with $3 \%$ agarose before and after ageing: (a) the historical sample before ageing; (b) aged historical sample; (c) treated historical sample (3\%) with Japanese gampi barrier before ageing, (d) treated historical sample with Japanese gampi barrier after ageing; (e) treated historical sample (3\%) with linen barrier before ageing, $(\mathrm{f})$ treated historical sample $(3 \%)$ with linen barrier after ageing; $(\mathrm{g})$ treated historical sample (3\%) with rayon barrier before ageing, and $(\mathrm{h})$ treated historical sample $(3 \%)$ with rayon barrier after ageing

Additionally, a dramatic decrease of impurities in the treated sample was noticed. The treated sample with pure linen barrier gave the best results, where the fibers became flexible and the surface appeared pure and cleaned.
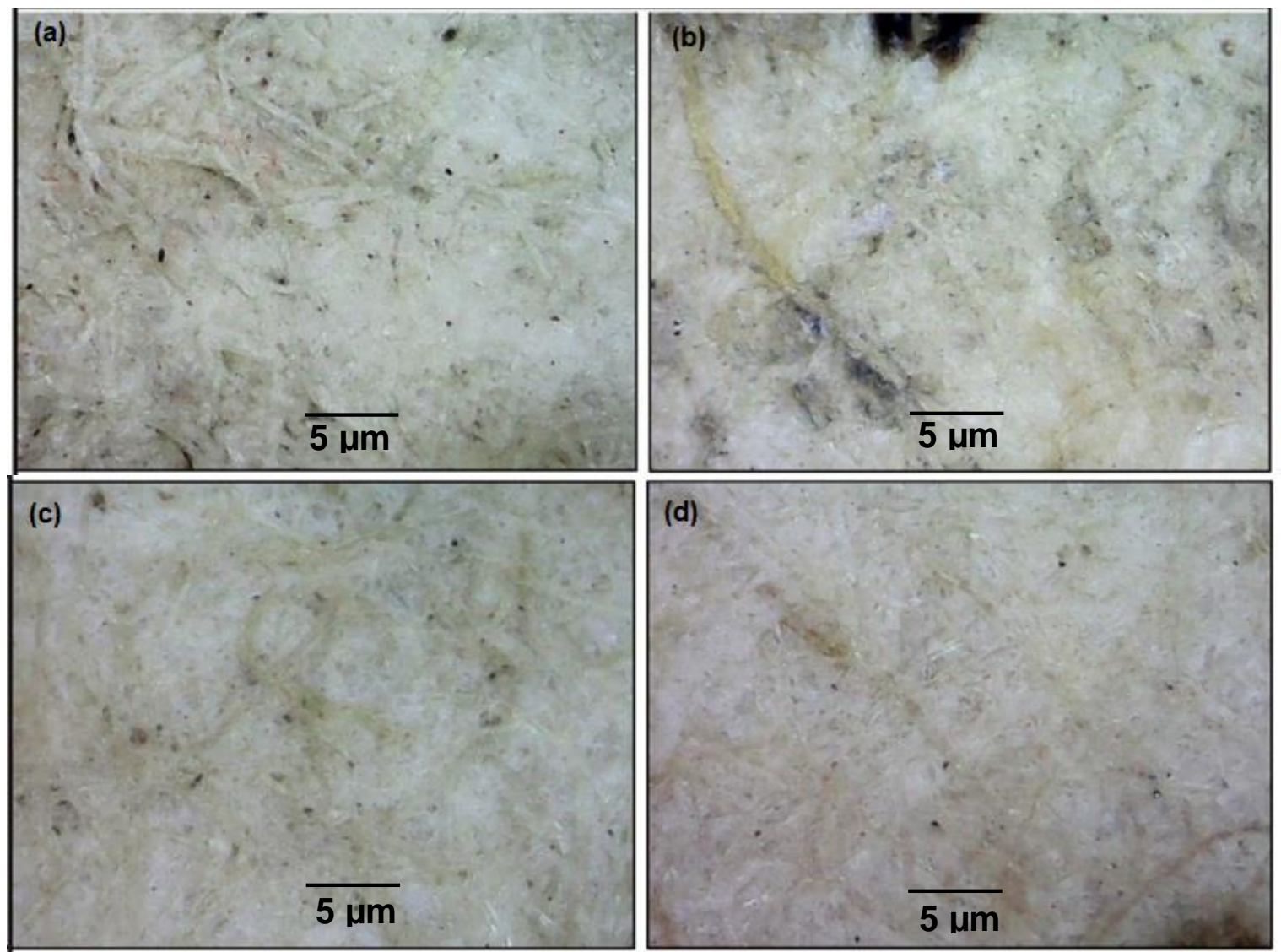

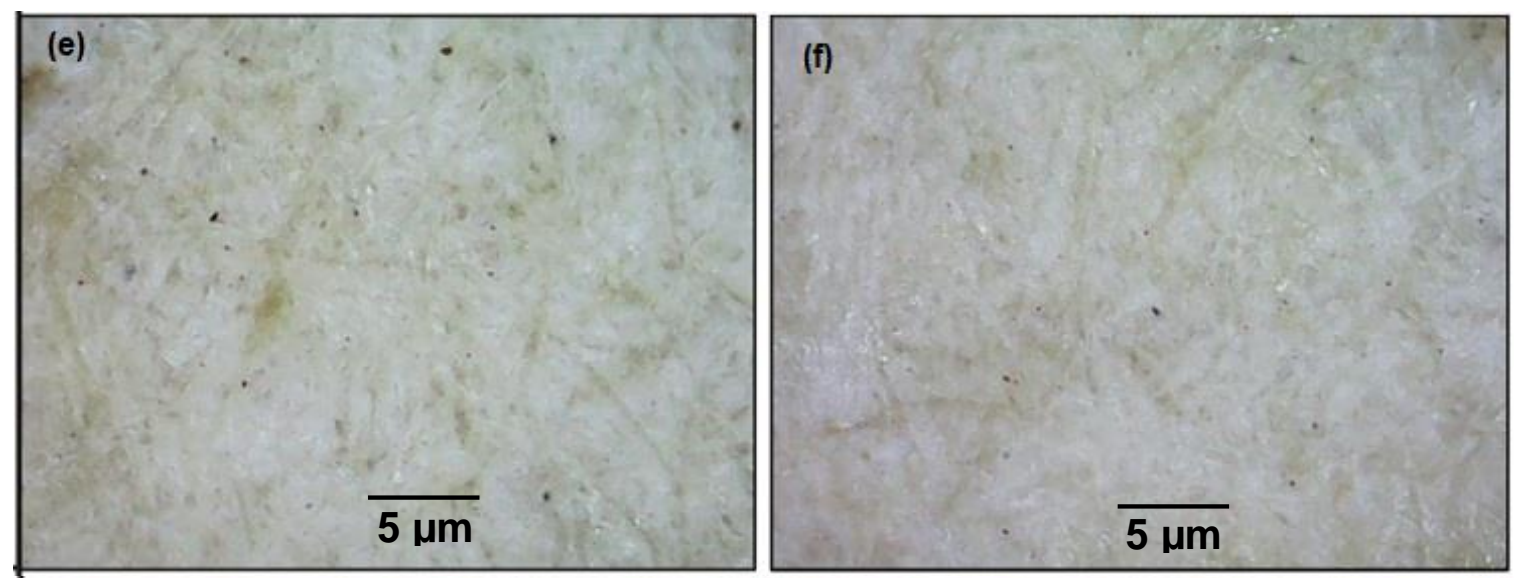

(g)

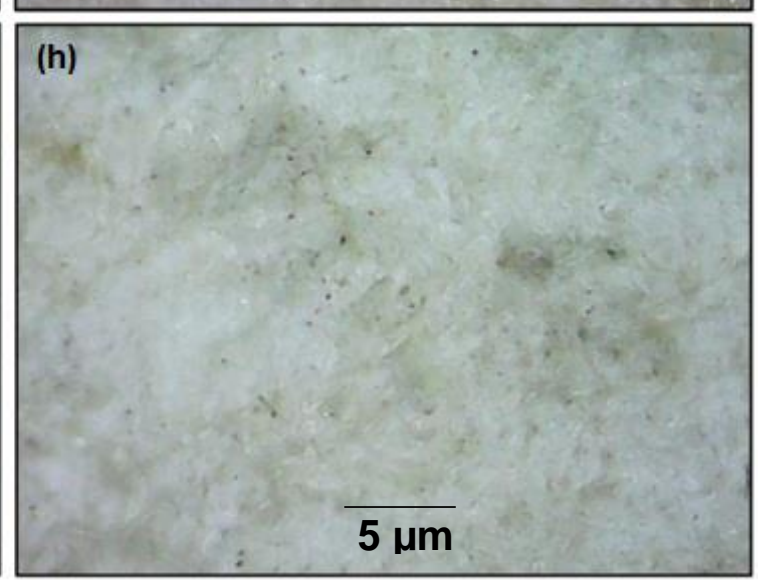

Fig. 6 (e-h). Images of optical micrographs (zoom $\times 40$ ) for treated paper samples with $6 \%$ agarose before and after ageing: (a) the historical sample before ageing; (b) aged historical sample; (c) treated historical sample (6\%) with Japanese gampi barrier before ageing, (d) treated historical sample with Japanese gampi barrier after ageing; (e) treated historical sample (6\%) with linen barrier before ageing, $(\mathrm{f})$ treated historical sample $(6 \%)$ with linen barrier after ageing; $(\mathrm{g})$ treated historical sample $(6 \%)$ with rayon barrier before ageing, and $(\mathrm{h})$ treated historical sample $(6 \%)$ with rayon barrier after ageing

In the case of the treated sample with rayon barrier, the ratio of the impurities was higher compared to when the linen barrier was used. From the obtained images from the optical microscope (Fig. 6) for the treated historical samples with agarose (6\%), it was found clearly that a large amount of impurities were on the surface of with using Japanese gampi barrier. While in the treated sample with agarose $(6 \%)$ and linen barrier, the fibres seemed flexible without the appearance of any residues. For the agarose $(6 \%)$ and rayon barrier, some residues were observed because of the treatment but it disappeared with ageing.

\section{Scanning Electron Microscope Analysis}

It was clear from the microscopic images (Figs. 7 and 8) that accelerated ageing impacted the structure of the untreated samples; an apparent destruction of untreated paper fibers was observed after the specimens had been subjected to ageing. Additionally, roughness of the fibers and the tearing deformation of paper fibers were also noticed.

After the treatment by both concentrations, no noticeable differences were detected. However, it was worth noting that an amount of residue was high at a concentration of $3 \%$ compared to a concentration of $6 \%$, which can be attributed to the decrease in viscosity in 
the concentration of $3 \%$. Furthermore, it was noted that the residue ratio decreased dramatically at $6 \%$ concentration. It was clear from the examination that there were borax residues that appeared on the fibers, but residues were less when pure linen was used compared with other samples, which was attributed to the low penetration of the remains (Fig. 8). Moreover, the linen barrier scored the best results, as the residues were minimum, followed by the Japanese gampi barrier, and finally the rayon barrier.

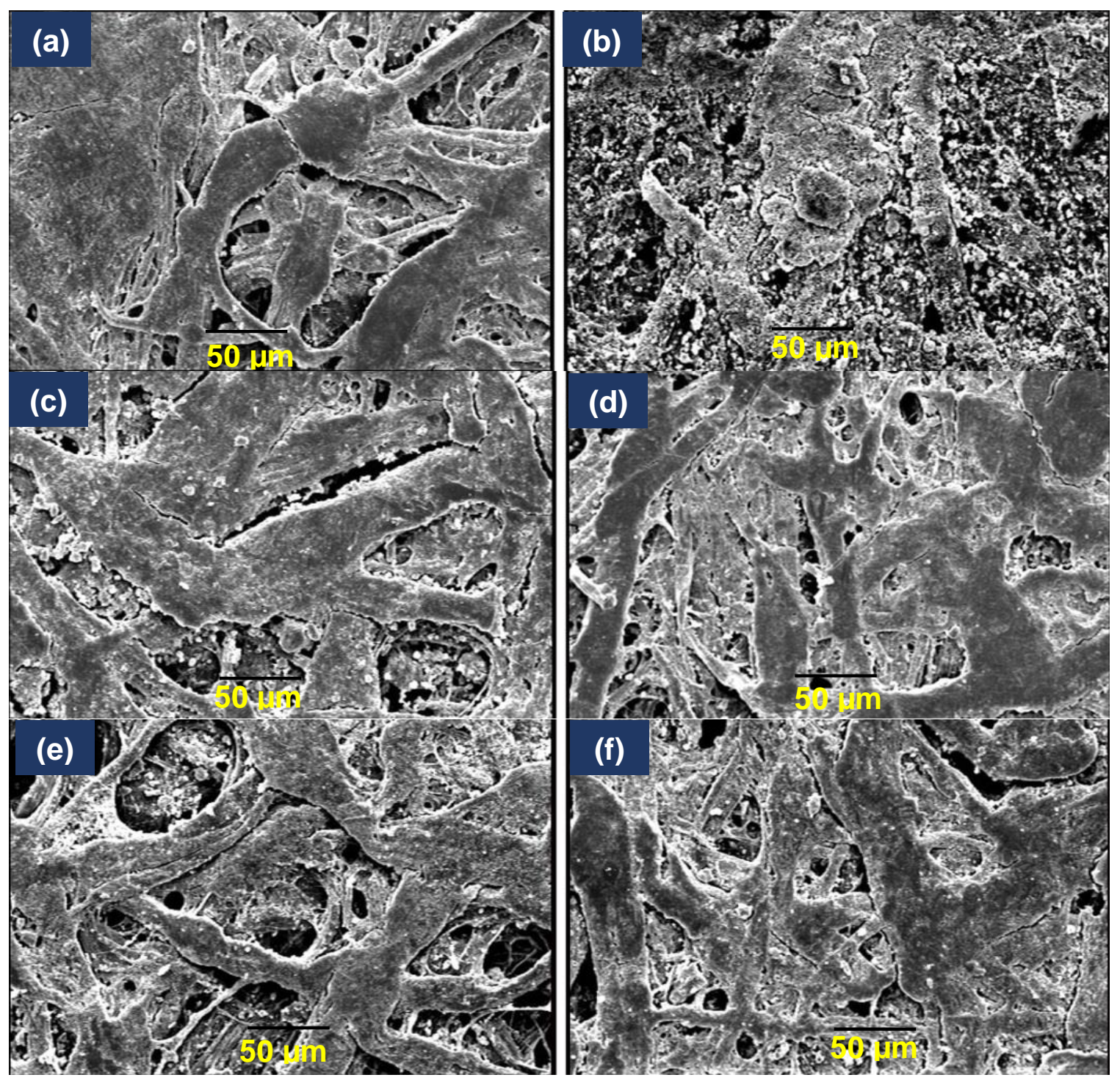

Fig. 7. The effect of the deacidification process on treated paper's surface with agar gel $3 \%$. Japanese gampi barrier (a) before ageing, (b) after ageing; linen barrier (c) before ageing, (d) after ageing; rayon barrier (e) before ageing, and (f) after ageing 


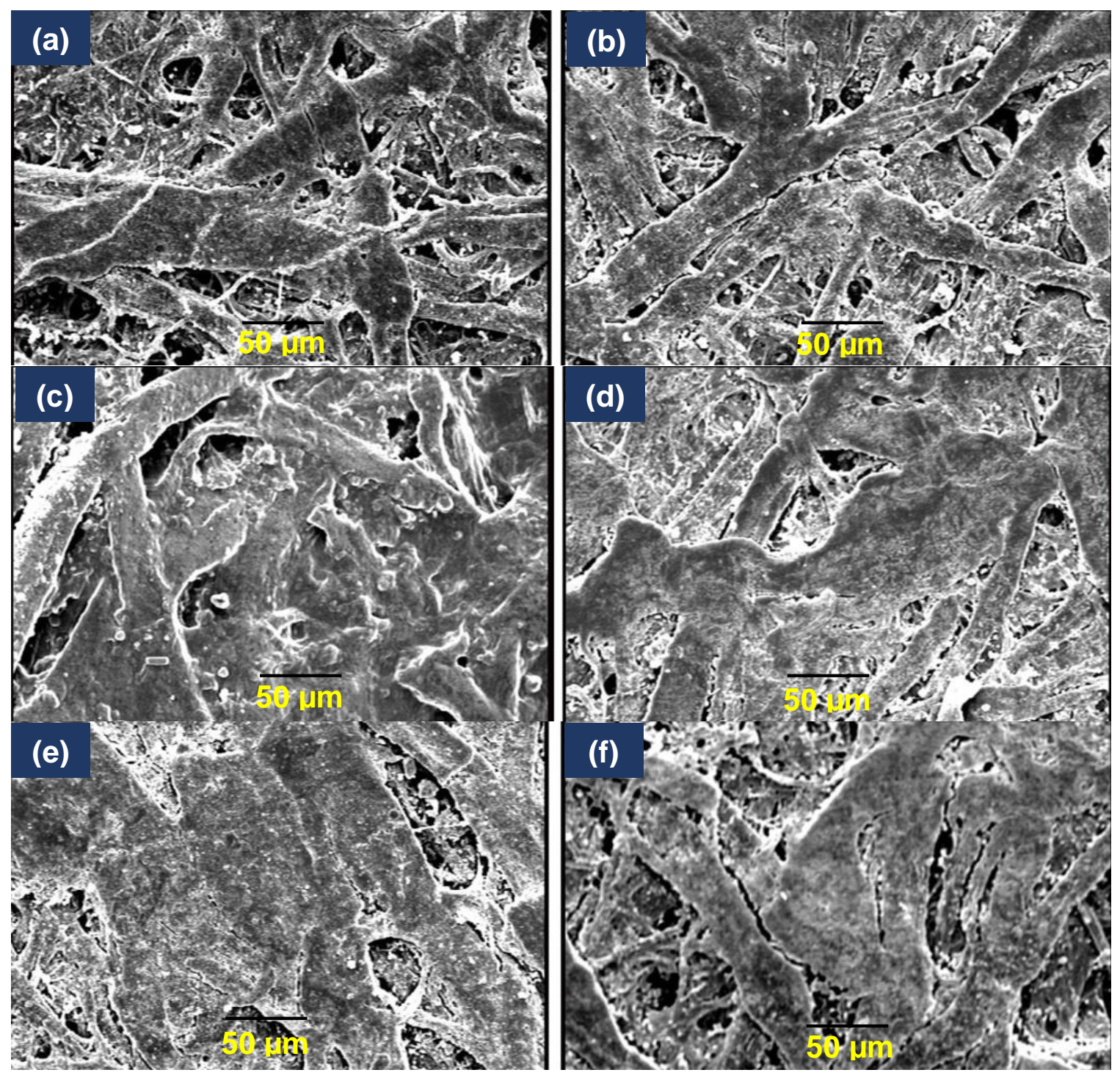

Fig. 8 (c-f). The effect of the deacidification process on treated paper surfaces treated with agar $6 \%$. Japanese gampi barrier (a) before ageing, (b) after ageing; linen barrier (c) before ageing, (d) after ageing; rayon barrier (e) before ageing, and (f) after ageing

\section{Color Change by Spectrophotometer}

Total colour differences $(\Delta E)$

Comparing the results of the colour change values for the samples $(\Delta E)$ before and after treatment (Table 2), it was noted that no noticeable colour change occurred in the treated samples with agarose poultice at the concentrations of $3 \%$ and $6 \%$ combined with different barriers except with treated samples (3\% and 6\%) by using the Japanese gampi barrier, for which the value of the $\Delta E$ was relatively high compared to the linen and rayon barriers. The results of the table confirmed that after the artificial ageing, the values of $\Delta E$ in all treated samples decreased significantly where $\Delta E$ of sample (A6L1) recorded 1.99 then the sample A6L0, which recorded (3.54), followed by sample A3L0 that was 6.7, then sample A3L1 that was 4.77. The apparent improvement in the values of the color change can be attributed to two reasons: i) role of the heat during the ageing in dryness of the residues ii) borax can react as a bleaching agent, which can improve the color change after 
aging a result of bleaching (Farr et al. 2003). There was also a clear difference between the values of the color change according to the type of barrier after the accelerating ageing

Where $\Delta E$ of the aged treated samples with linen barrier $\mathrm{A}_{6} \mathrm{~L}_{1}$ and $\mathrm{A}_{3} \mathrm{~L}_{1}$ recorded 1.99 and 4.77 respectively, which confirmed that the linen barrier had a pivotal role in reducing the values of colour change.

Comparing these results, it was observed that the lowest degree of colour change was in the sample treated with the poultice concentration of $6 \%$ and the use of pure linen as a barrier. This was followed by the treated sample with concentration $3 \%$ and the use of rayon as a barrier (after ageing). Next, was the treated sample with a concentration of $6 \%$ and the use of rayon as a barrier, then the treated sample with the poultice concentration $3 \%$ and the rayon as a barrier (after treatment without ageing), then the treated sample with concentration of 3\% with Japanese gampi barrier (after ageing), and lastly the treated sample with a concentration of $6 \%$ using a Japanese gampi barrier.

Table 2. Total Colour Differences of Treated Samples Before and After Ageing

\begin{tabular}{|c|c|c|c|c|c|c|c|c|c|}
\hline & & Agar 3 & & & & & & $\operatorname{ar} 6 \%$ & \\
\hline Sample & Col & ur Va & & & Sample & & ur Val & & Total \\
\hline & $L$ & $a$ & $b$ & $\Delta E$ & & $L$ & $a$ & $b$ & $\Delta E$ \\
\hline $\begin{array}{c}\text { Standa } \\
\text { rd }\end{array}$ & 77.93 & 3.50 & 20.06 & 0.0 & Standard & 77.94 & 3.50 & 20.06 & 0.0 \\
\hline $\mathrm{A}_{3} \mathrm{G}_{0}$ & 79.006 & 3.05 & 17.01 & 3.29 & $\mathrm{~A}_{6} \mathrm{G}_{0}$ & 68.19 & 4.78 & 15.27 & 10.94 \\
\hline $\mathrm{A}_{3} \mathrm{G}_{1}$ & 68.25 & 4.43 & 15.07 & 10.94 & $\mathrm{~A}_{6} \mathrm{G}_{1}$ & 72.57 & 4.05 & 16.12 & 6.68 \\
\hline$A_{3} L_{0}$ & 71.64 & 4.05 & 17.67 & 6.76 & $A_{6} L_{0}$ & 75.50 & 3.60 & 17.50 & 3.54 \\
\hline$A_{3} L_{1}$ & 81.04 & 2.15 & 16.69 & 4.77 & $\mathrm{~A}_{6} \mathrm{~L}_{1}$ & 77.76 & 3.32 & 18.09 & 1.99 \\
\hline $\mathrm{A}_{3} \mathrm{R}_{0}$ & 71.02 & 4.09 & 14.62 & 8.82 & $\mathrm{~A}_{6} \mathrm{R}_{0}$ & 78.25 & 3.08 & 16.17 & 3.93 \\
\hline $\mathrm{A}_{3} \mathrm{R}_{1}$ & 81.42 & 1.78 & 14.39 & 6.87 & $\mathrm{~A}_{6} \mathrm{R}_{1}$ & 72.57 & 3.81 & 15.64 & 6.96 \\
\hline
\end{tabular}

Subscript ' 1 ' refers to after ageing and ' 0 ' refers to before ageing

\section{The pH Measurement}

The results shown in Table 2 show that the $\mathrm{pH}$ value for the historical sample was 4.5 , and this value can be regarded as an initial stage of the oxidation process. It was stated that fibers made of cellulose chains are degraded when exposed to an acidic environment in the presence of moisture. In this case, the acid hydrolysis reaction can occur, such that cellulose chains are repeatedly split into smaller fragments as long as the source of acid remains in the paper. This acid hydrolysis reaction produces more acid and accelerates the degradation (Block et al. 1958).

After treatment, a dramatic change was observed, where the values of $\mathrm{pH}$ increased. Table 3 shows that the $\mathrm{A}_{3} \mathrm{~L}_{0}$ sample gave the best result in the concentration of $3 \%$, after ageing $\left(\mathrm{A}_{3} \mathrm{~L}_{1}\right)$ the result was still higher than the untreated sample, which confirms that the treatment $(3 \%)$ helped to prevent the oxidation of the paper during the ageing and gave an acceptable $\mathrm{pH}$ value.

It also indicated the success of the linen barrier in achieving the desired goal of treatment, which was to neutralize the acidity efficiently. With rayon and gampi barriers (samples $\mathrm{A}_{3} \mathrm{G}_{0}$ and $\mathrm{A}_{3} \mathrm{R}_{0}$ ) it achieved a high $\mathrm{pH}$ level. This may be due to the penetration of the agarose into the pores of the paper, and this did not fit the goals of treatment with poultice. However, after the ageing, the samples $A_{3} G_{1}$ and the sample $A_{3} R_{1}$ reached a 
neutral level. As for the $6 \%$ concentration in the sample $\mathrm{A}_{6} \mathrm{~L}_{0}$ and the sample $\mathrm{A}_{6} \mathrm{~L}_{1}$, it appeared that the higher concentration of the poultice with pure linen as a barrier did not help in penetration of the substance well, where $\mathrm{pH}$ values increased slightly after treatment.

For the samples A6G0, A6G1, A6R0, and A6R1, it appeared that gampi and rayon helped achieve the deacidification of treated paper $(3 \%)$ compared to the linen barrier. Where the $\mathrm{pH}$ values of treated paper reached suitable values, as well as after ageing, the $\mathrm{pH}$ level was ideal. According to these results, it is recommended to use low concentrations of the poultice (approximately 3\%) with pure linen as a barrier. This was because it reduced the residues after treatment.

Beside that, gampi or rayon barriers should be used in the case of a high concentration of agarose, because they allowed the penetration of the treatment particles by the required ratio. The results are consistent with what has been demonstrated by specialists in the field of paper acidity deacidification; paper preservation from acid hydrolysis as well as from the corrosion of oxidative ink has been achieved by stabilizing the final $\mathrm{pH}$ of de-acidifying paper around 6.5 to 7.5 (Poggi et al. 2010).

Table 3. The $\mathrm{pH}$ Values of Treated Samples

\begin{tabular}{|c|c|}
\hline Samples & $\mathrm{pH}$ \\
\hline Standard & $4: 5$ \\
\hline $\mathrm{A}_{3} \mathrm{~L}_{0}$ & $7.5: 8$ \\
\hline $\mathrm{A}_{3} \mathrm{~L}_{1}$ & 6 \\
\hline $\mathrm{A}_{3} \mathrm{G}_{0}$ & $8.5: 9$ \\
\hline $\mathrm{A}_{3} \mathrm{G}_{1}$ & $7: 7.5$ \\
\hline $\mathrm{A}_{3} \mathrm{R}_{0}$ & $8.5: 9$ \\
\hline $\mathrm{A}_{3} \mathrm{R}_{1}$ & $7.5: 8$ \\
\hline $\mathrm{A}_{6} \mathrm{~L}_{0}$ & $5.5: 6$ \\
\hline $\mathrm{A}_{6} \mathrm{~L}_{1}$ & 5.5 \\
\hline $\mathrm{A}_{6} \mathrm{G}_{0}$ & $8: 8.5$ \\
\hline $\mathrm{A}_{6} \mathrm{G}_{1}$ & $7.5: 8$ \\
\hline $\mathrm{A}_{6} \mathrm{R}_{0}$ & $8: 8.5$ \\
\hline $\mathrm{A}_{6} \mathrm{R}_{1}$ & $7.5: 8$ \\
\hline
\end{tabular}

\section{FTIR Results}

Figure 9 shows the FTIR spectra of control and treated samples before and after ageing. For an aged untreated specimen it was interesting to note that after ageing there were some differences in the decrease of the relative intensity of the $\mathrm{O}-\mathrm{H}$ group at 3400 $\mathrm{cm}^{-1}$, and the shape change of this peak may be an indication of the rate increase of evaporation. Secondly, it increased molecular mobility. In addition, the $876 \mathrm{~cm}^{-1}$ bands that represent the $\mathrm{C}-\mathrm{H}$ stretch third overtone disappeared. The intensity of the carboxylic peak near $1600 \mathrm{~cm}^{-1}$ also increased with ageing.

FT-IR spectra of treated sample showed vibrational peaks at $3419.3 \mathrm{~cm}^{-1}$, and $3421.9 \mathrm{~cm}^{-1}$, which indicates the presence of O-H stretching. Furthermore, an absorption band was found at $2900 \mathrm{~cm}^{-1}$, which is associated with methoxyl group, while vibrational band occurred at $1600 \mathrm{~cm}^{-1}$ presented the $\mathrm{CO}$ and $\mathrm{NH}$ groups, which are responsible for the formation of conjugated peptide bonds. It is also observed that the presence of a band at $930 \mathrm{~cm}^{-1}$, in (Figs. 10 to 14) indicated the presence of 3,6-anhydrogalactose bridges. 
Furthermore, the borax spectrum bands at 1420, 1150, 1079, 1000, 949, and $832 \mathrm{~cm}^{-1}$ were detected in all treated samples.

However, it should be noted that FTIR spectra also showed that there was a difference in the amount of residues on the samples according to barriers types. This difference was as follows: with linen, a barrier a dramatic decrease in intensities of starching bands at $1073.3 \mathrm{~cm}^{-1}$ and $1150 \mathrm{~cm}^{-1}$ was observed. Furthermore, the intensities of borax bands at 1420,1079 and $1150 \mathrm{~cm}^{-1}$ decreased observably as compared to other barriers. On other hand, the agar and borax bands intensities increased with use of rayon and the gampi as barriers. However, those bands their intensities decreased after ageing because part of these materials could be subjected to oxidation resulting from the process of ageing as shown in Figs. 10 to 14.

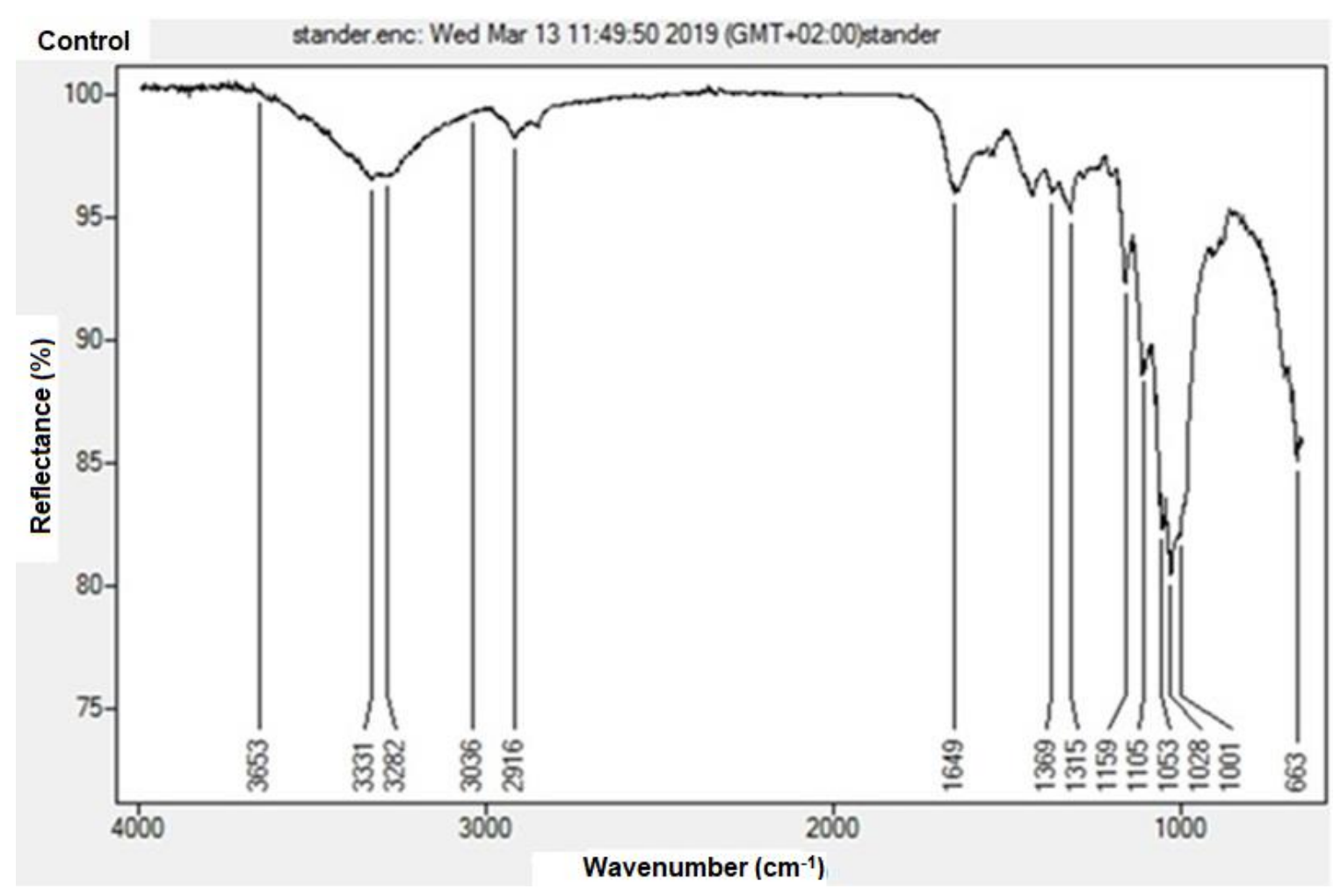




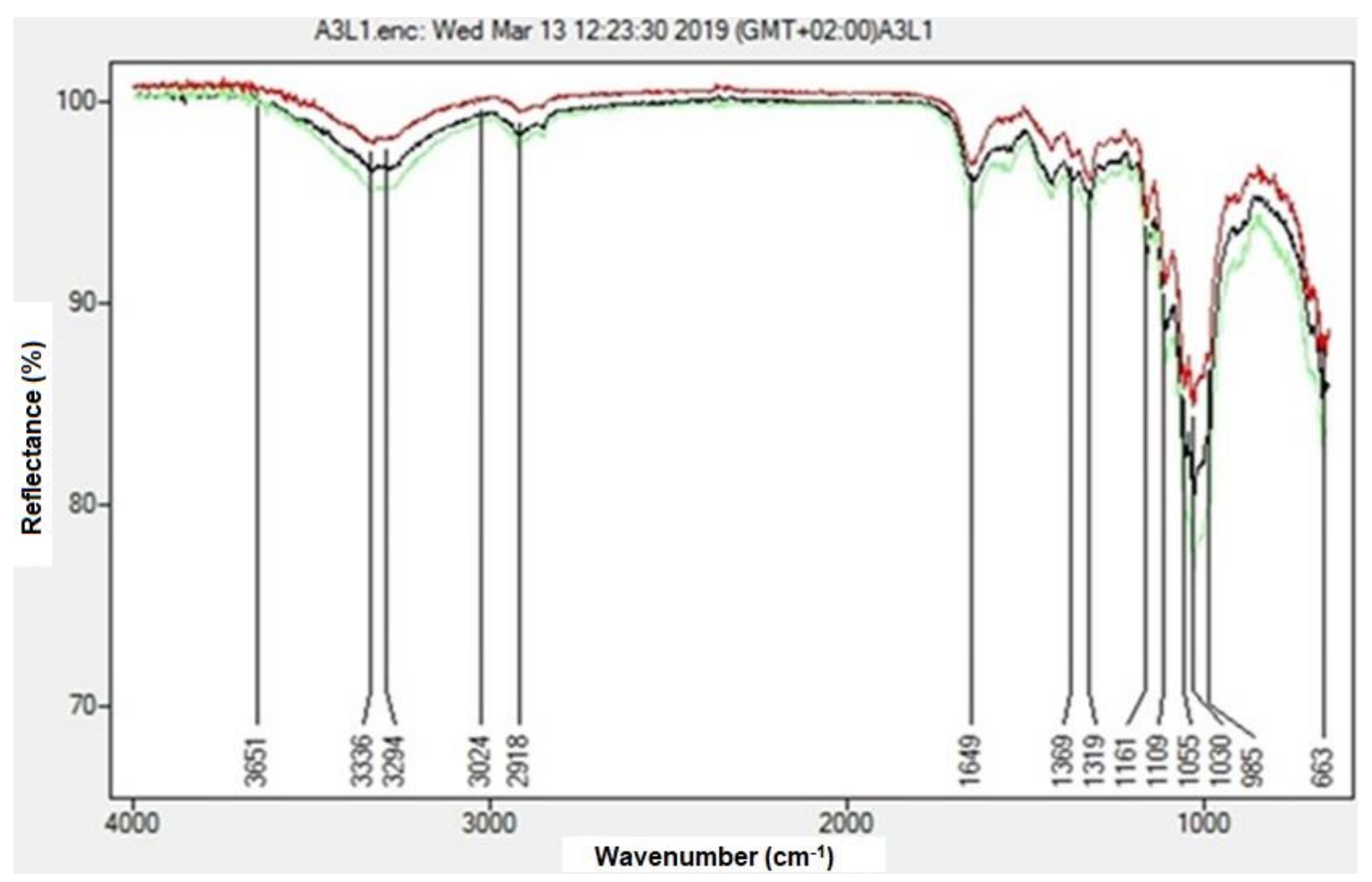

Fig. 9. FTIR spectra of control sample (above) and treated samples with $3 \%$ agar poultice and linen barrier: standard (black); $A_{3} L_{0}$ (red); $A_{3} L_{1}$ (green)

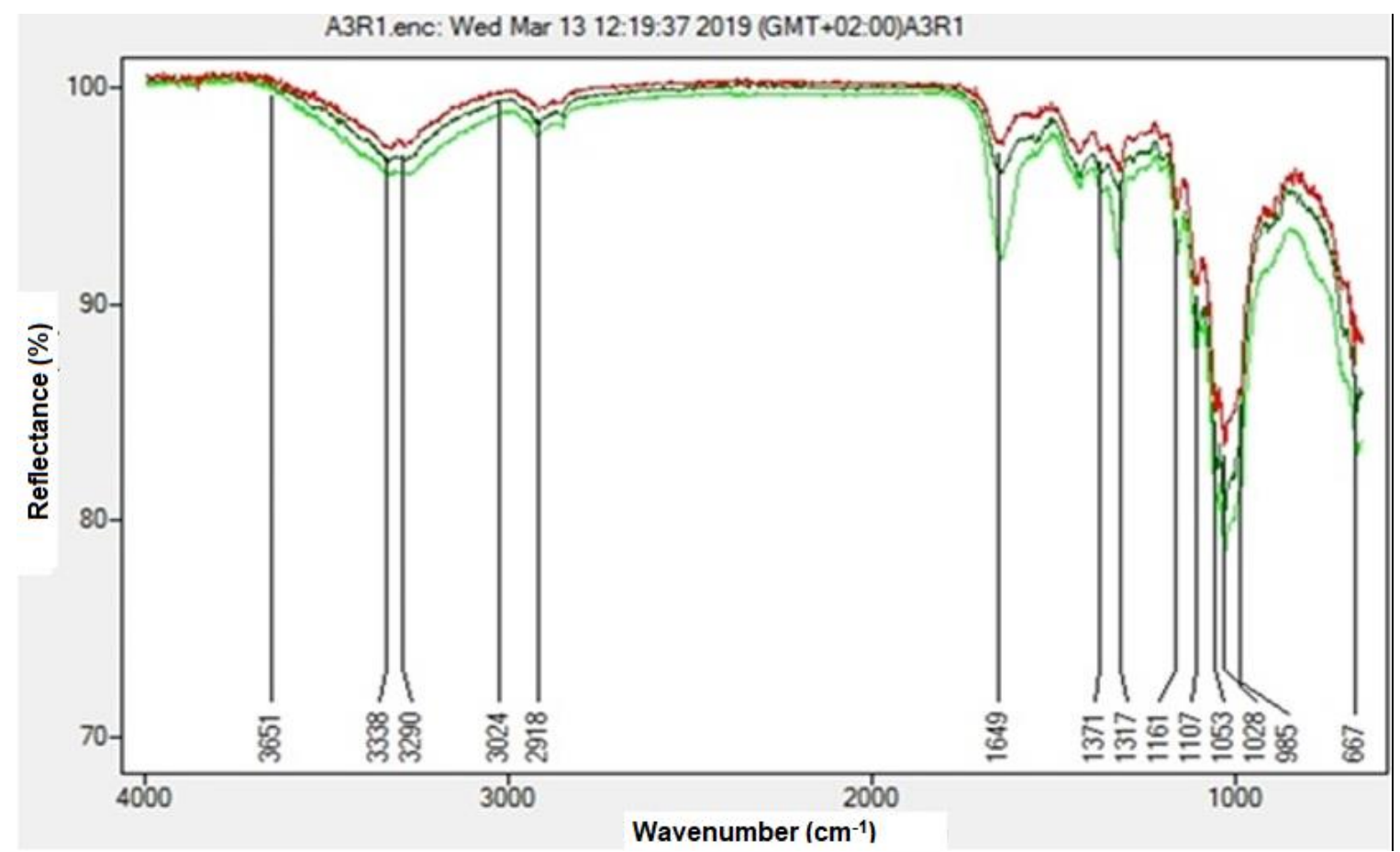

Fig. 10. The FTIR spectra of treated samples with $3 \%$ agar poultice and rayon barrier: standard (black); $A_{3} R o$ (red); $A_{3} R 1$ (green) 


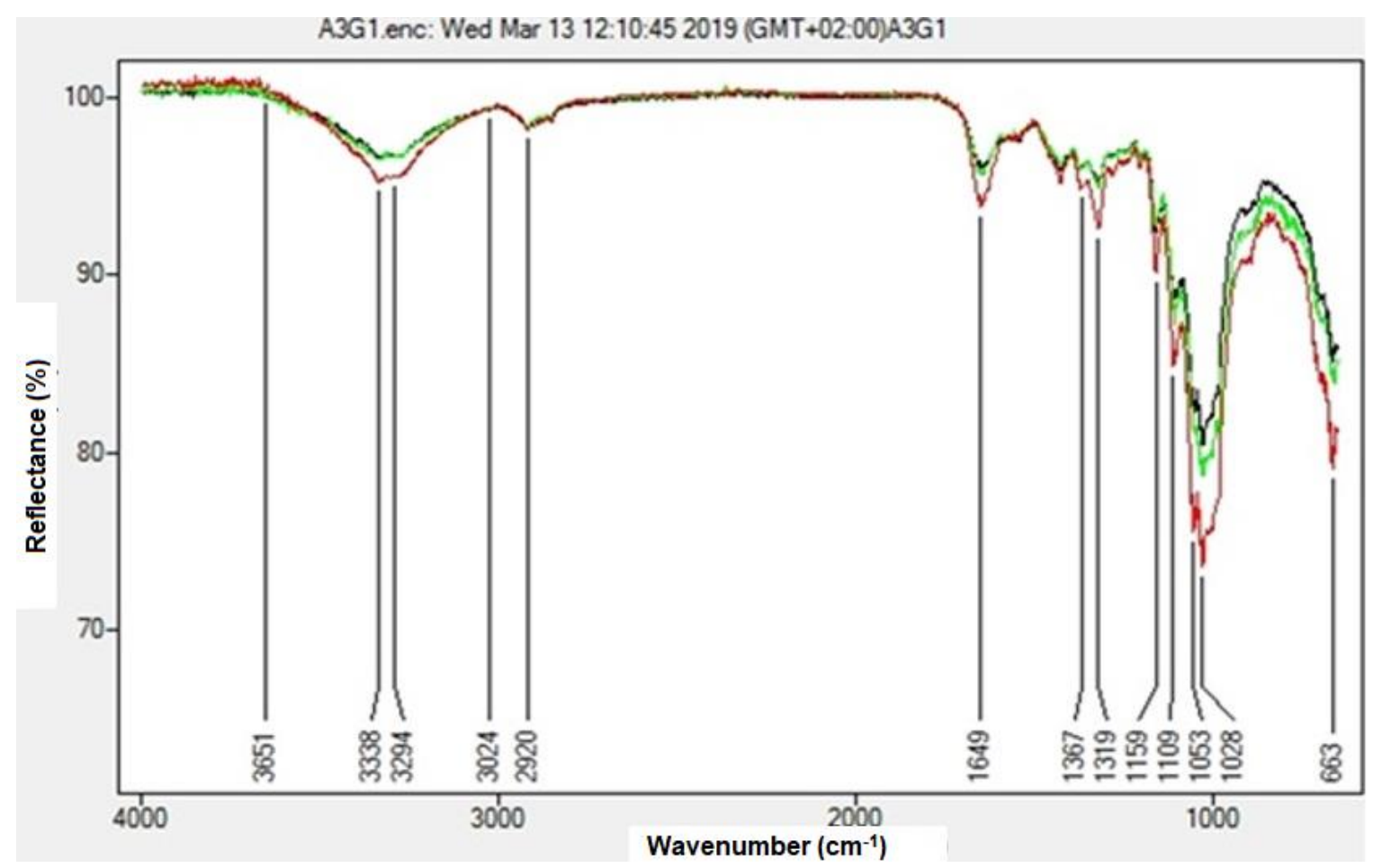

Fig. 11. The FTIR spectra of treated samples with $3 \%$ agar poultice and gampi barrier: standard (black); $A_{3} G_{0}$ (red); $A_{3} G_{1}$ (green)

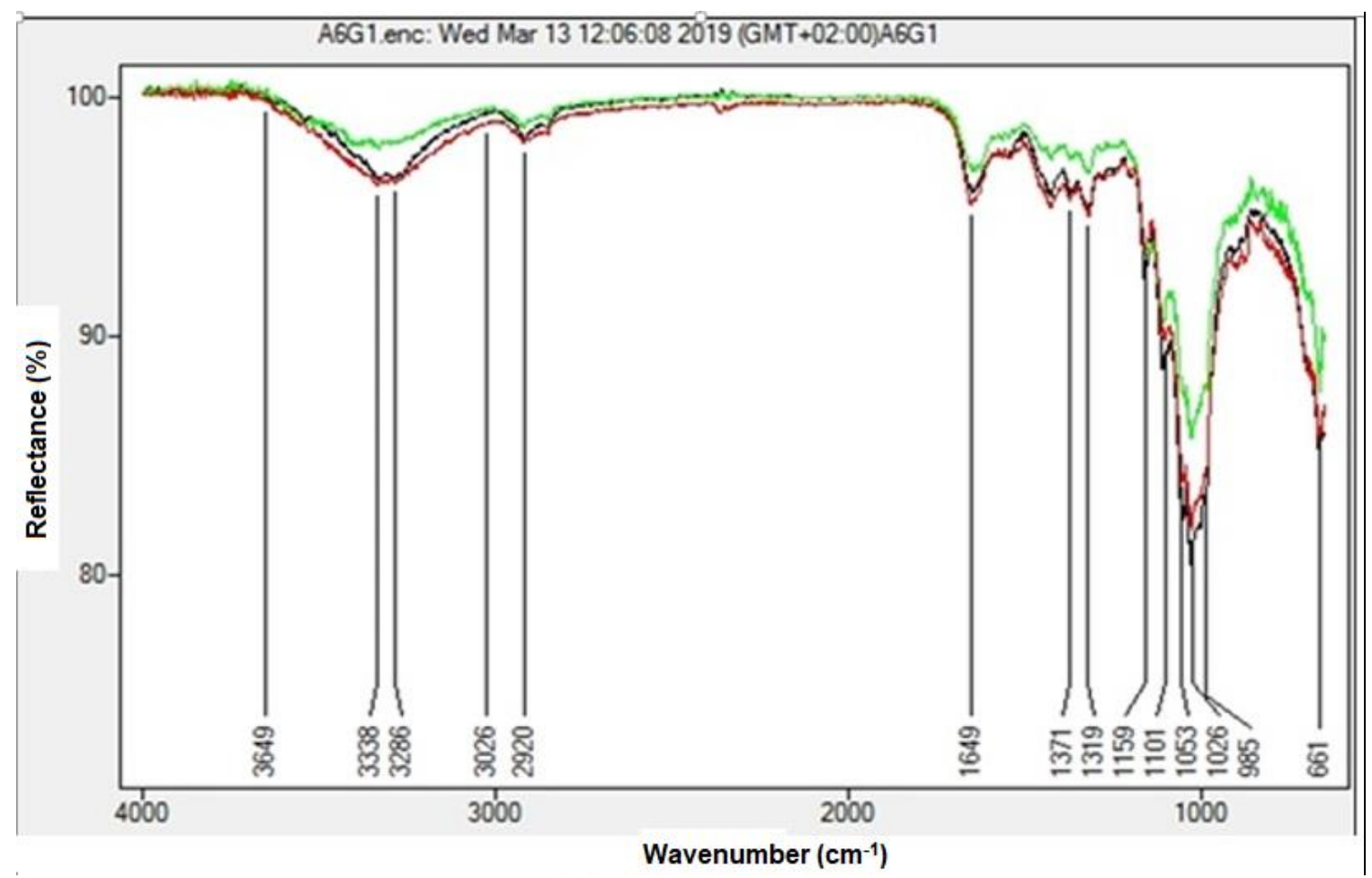

Fig. 12. The FTIR spectra of treated samples with $6 \%$ agar poultice and gampi barrier: standard (black); $A_{6} G_{0}$ (red); $A_{6} G_{1}$ (green) 


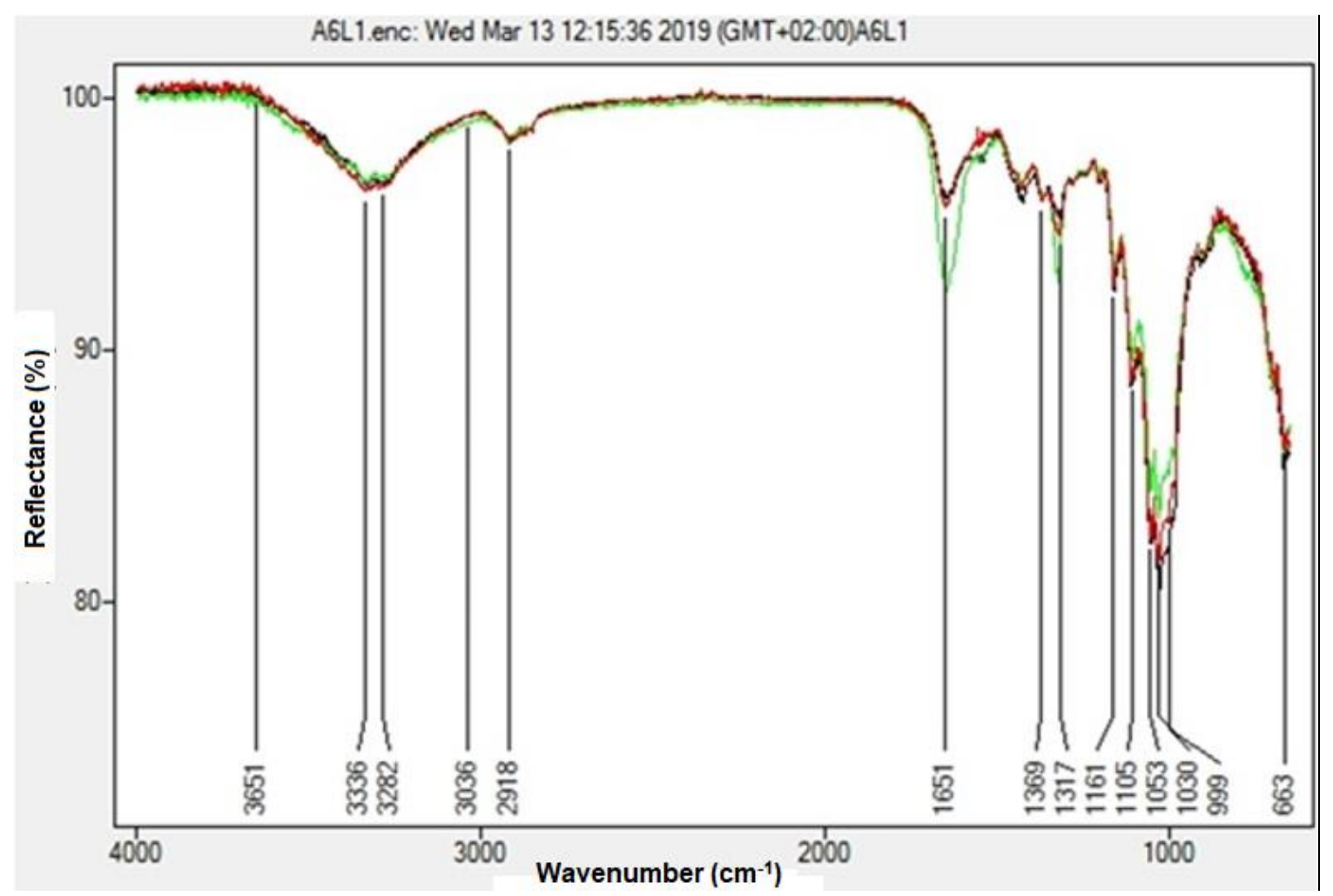

Fig. 13. FTIR spectra of treated samples with $6 \%$ agar poultice and linen barrier: standard (black); $A_{6} L_{0}$ (red); $A_{6} L_{1}$ (green)

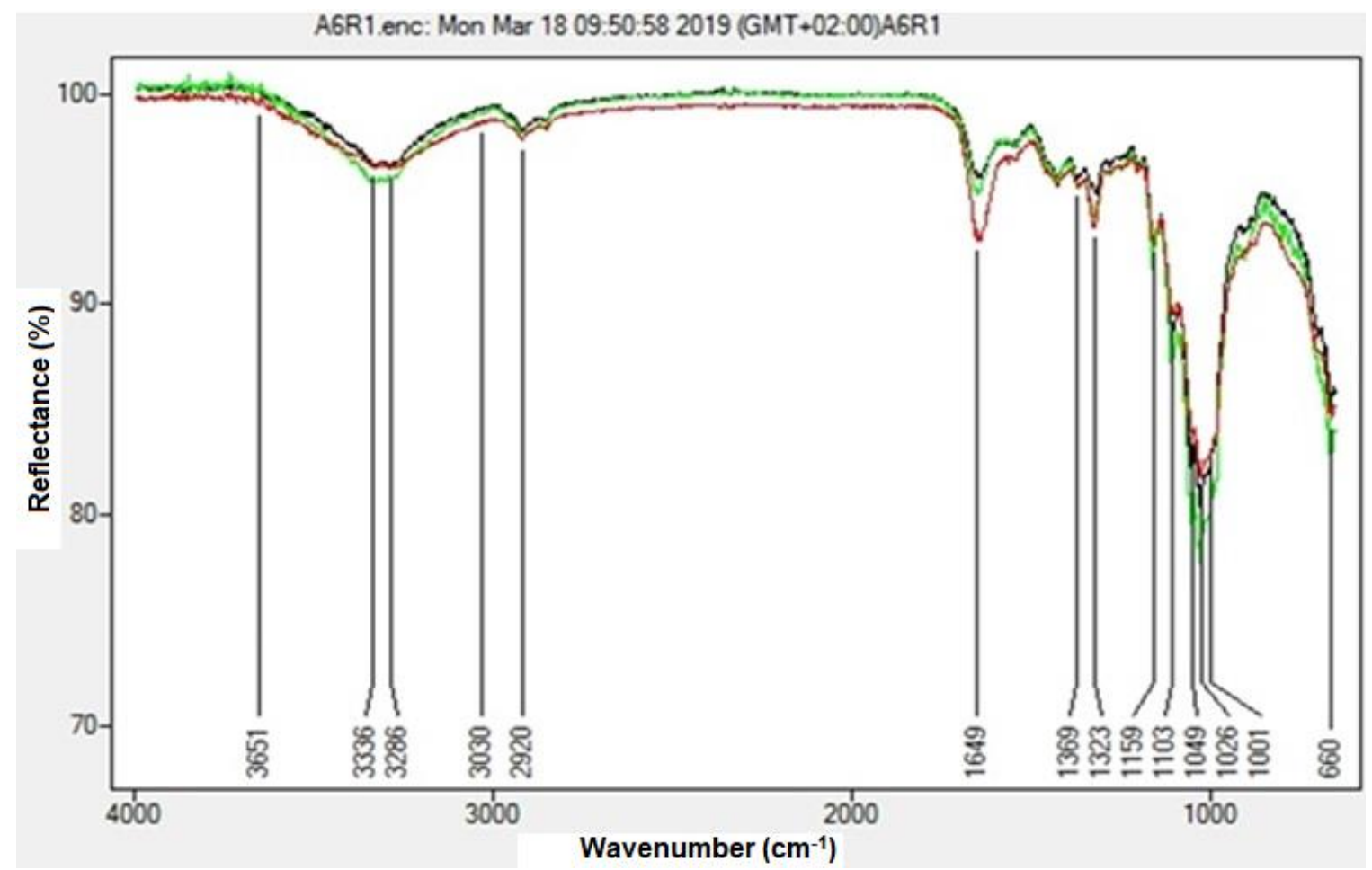

Fig. 14. FTIR spectra of treated samples with $6 \%$ agar poultice and rayon barrier: standard (black); $A_{6} R_{\circ}$ (red); $A_{6} R_{1}$ (green) 


\section{CONCLUSIONS}

1. The results confirmed that the concentration of $3 \%$ of borax poultice gave the best results in treatment with no residue left, especially when using the linen as barrier. The optical microscope images confirmed that the treated fibers became more flexible after treatment. Additionally, a dramatic decrease of impurities in the treated sample was noticed.

2. This study provided that it was preferable to use high concentrations for highly sensitive objects that did not bear the high moisture content.

3. The use of barriers greatly reduced residues resulting from the use of a poultice, especially the linen barrier, as demonstrated by the results of FTIR where the intensities of agar and borax bands at 1420 and $1150 \mathrm{~cm}^{-1}$ reduced dramatically in treated samples with linen barrier.

4. One of the striking results was the decrease in the color change values of the samples treated by borax poultice after artificial ageing where the result of $\Delta E$ value confirmed that the poultice in the current study recorded acceptable $\Delta E$ values, which cannot be detected by naked eye.

5. Linen barrier with a concentration of $3 \%$ gave promising results for the deacidification, even after artificial ageing where a dramatic change was observed in the values of $\mathrm{pH}$ that increased observably after treatment even after aging the result was still higher than the untreated sample which confirmed that the treatment (3\%) helped to prevent the oxidation of the paper during the ageing and gave an acceptable $\mathrm{pH}$ value.

6. Treatment with borax poultice increased the intensity of $-\mathrm{OH}$ stretching band notably that helps improve the mechanical and physical characters of paper manuscripts.

\section{ACKNOWLEDGMENTS}

This research was funded by the Researchers Supporting Project (RSP-2020/123) from King Saud University, Riyadh, Saudi Arabia.

\section{REFERENCES CITED}

Alam, M. N., Antal, M., Tejado, A., and van de Ven, T. G. (2012). "Salt-induced acceleration of chemical reactions in cellulose nanopores," Cellulose 19(2), 517-522.

Ali, M. F., Mansour, M. M. A., Mohamed, N. B., and Salem, M. Z. M. (2018). "A study of biodeterioration and chromatic alterations of painted and gilded mummy cartonnage at the Saqqara Museum Storeroom, Egypt," Archaeometry 60(4), 845858. DOI: $10.1111 /$ arcm. 12340

Agrawal, P., and Barkeshli, M. (1997). Conservation of Books, Manuscripts and Paper Documents, Indian Council of Conservation, Institutes Luck now, 1997, p. 111.

Angelova, L. V., Berrie, B. H., de Ghetaldi, K., Kerr, A., and Weiss, R. G. (2015). "Partially hydrolyzed poly (vinyl acetate)-borax-based gel-like materials for 
conservation of art: Characterization and applications," Studies in Conservation 60(4), 227-244. DOI: 10.1179/2047058413Y.0000000112

Badea, E., Della Gatta, G., and Usacheva, T. (2012). "Effects of temperature and relative humidity on fibrillar collagen in parchment: A micro differential scanning calorimetry (micro DSC) study," Polymer Degradation and Stability 97(3), 346-353. DOI:

10.1016/j.polymdegradstab.2011.12.013

Bae, S., Sugano, Y., and Shoda, M. (2004). "Improvement of bacterial cellulose production by addition of agar in a jar fermentor," Journal of Bioscience and Bioengineering 97(1), 33-38. DOI: 10.1016/S1389-1723(04)70162-0.

Baglioni, P., Dei, L., Carretti, E., and Giorgi, R. (2009). "Gels for the conservation of cultural heritage," Langmuir 25(15), 8373-8374. DOI: 10.1021/la900961k

Baty, J. W., Maitland, C. L., Minter, W., Hubbe, M. A., and Jordan-Mowery, S. K. (2010). "Deacidification for the conservation and preservation of paper-based works: A review," BioResources 5(3), 1955-2023. DOI: 10.15376/biores.5.3.Baty

Block, R. J., Durrum, E. L., and Zweig, G. (1958). "Paper chromatography," in: A Manual of Paper Chromatography and Paper Electrophoresis, $2^{\text {nd }}$ Ed., Academic Press, New York, NY, USA, pp. 75-80.

Brunetti, F., Operamolla, A., Castro-Hermosa, S., Lucarelli, G., Manca, V., Farinola, G. M., and Brown, T. M. (2019). "Printed solar cells and energy storage devices on paper substrates," Advanced Functional Materials 29(21), Article ID 1806798. DOI: 10.1002/adfm.201806798

Campbell, A., Hamilton, A., Stratford, T., Modestou, S., and Ioannou, I. (2011). "Calcium hydroxide nanoparticles for limestone conservation: Inhibition and adhesion," in: CCI Symposium, Adhesives and Consolidants for Conservation: Research and Applications, Ottawa, Canada, pp. 17-21.

Cremonesi, P. (2016). "Surface cleaning? Yes, freshly grated agar gel, please," Studies in Conservation 61(6), 362-367. DOI: 10.1179/2047058415Y.0000000026.

Devanathan, R. (2012). "Conservation of manuscripts-The natural way," International Journal of Current Pharmaceutical Review and Research 3(4), 99-104.

Domingues, J., Bonelli, N., Giorgi, R., Fratini, E., and Baglioni, P. (2013). "Innovative method for the cleaning of water sensitive artefacts: Synthesis and application of highly retentive chemical hydrogels," International Journal of Conservation Science 4, 715-722.

Elamin, A., Takatori, K., Matsuda, Y., Tsukada, M., and Kirino, F. (2018a). "Microbiological, morphological and spectroscopic study on the effect of resinous materials in the preservation of wrapping textiles of mummies," Mediterranean Archaeology and Archaeometry 18(2), 1-10. DOI: 10.5281/zenodo.1297142

Elamin, A., Takatori, K., Matsuda, Y., Tsukada, M., and Kirino, F. (2018b). "Fungal biodeterioration of artificial aged linen textile: Evaluation by microscopic, spectroscopic and viscometric methods," Mediterranean Archaeology and Archaeometry 18(3), 103-120. DOI: 10.5281/zenodo.1461623

Ellis, M., and Ellis, P. J. (1997). Microfungi on Land Plants: An Identification Handbook, The Richmond Publishing Co., Ltd., London, England.

El-Feky, O. M., Hassan, E. A., Fadel, S. M., and Hassan, M. L. (2014). "Use of ZnO nanoparticles for protecting oil paintings on paper support against dirt, fungal attack, and UV aging," Journal of Cultural Heritage 15(2), 165-172. DOI:

10.1016/j.culher.2013.01.012 
Fan, H., Li, G., Yang, F., Yang, L., and Zhang, S. (2011) "Photodegradation of cellulose under UV light catalysed by $\mathrm{TiO}_{2}$," Journal of Chemical Technology and Biotechnolology 86(8), 1107-1112. DOI: 10.1002/jctb.2632

Farr, J. P., Smith, W. L., and Steichen, D. S. (2003). "Bleaching agents," in: Kirk Othmer Encyclopedia of Chemical Technology. DOI:10.1002/0471238961.1921182206011818.a01.pub2

Feller, R. L. (1994). "Accelerated aging: Photochemical and thermal aspects," in: Research in Conservation, D. Berland (ed.), The J. Paul Getty Trust, Los Angeles, CA, USA.

George, W. (1995). Handbook of Material Weathering, $2^{\text {nd }}$ Ed. Chem. Tec, Ontario, Canada.

Granan, D., Hilaire, J. S., Burgess, H. D., and McCawley, C. (1987). "Chapter 2.1 Scientific Developments: The characterization of enzymes for use in paper conservation," in: Conservation of Library and Archive Materials and the Graphic Arts, G. Petherbridge (ed.), Butterworths, London, England, pp. 15-24.

Hamed, S. A. E. K. M., and Hassan, R. R. A. (2019). "Microscopic characterization of acidic paper manuscripts," Pigment and Resin Technology 48(2), 119-128. DOI: 10.1108/PRT-05-2018-0048

Hassan, R. R. A. (2015). "Behavior of archeological paper after cleaning by organic solvents under heat accelerated ageing," Mediterranean Archaeology and Archaeometry 15(3), 141-150. DOI: 10.5281/zenodo.18365

Hassan R. R. A. (2016). "Thermal degrading of paper: The structure changes of fibres," Egyptian Journal of Archaeological and Restoration Studies 6(2), 71-84.

Hassan, R. R. A., and Mohamed, W. S. (2017). "Effect of methyl methacrylate/ hydroxyethyl methacrylate copolymer on optical and mechanical properties and longterm durability of paper under accelerated ageing," International Journal of Conservation Science 8(2), 237-250.

Hassan, R. R. A., and Mohamed, W. S. (2018). "The impact of methyl methacrylate hydroxyethyl methacrylate loaded with silver nanoparticles on mechanical properties of paper," Applied Physics A 124(8), 551-555. DOI: 10.1007/s00339-018-1989-3

Hinterstoisser, B., and Salmén, L. (2000). "Application of dynamic 2D FTIR to cellulose," Vibrational Spectroscopy 22(1-2), 111-118. DOI: 10.1016/S09242031(99)00063-6

Hubbe, M. A., Smith, R. D., Zou, X., Katuscak, S., Potthast, A., and Ahn, K. (2017). "Deacidification of acidic books and paper by means of non-aqueous dispersions of alkaline particles: A review focusing on completeness of the reaction," BioResources 12(2), 4410-4477. DOI: 10.15376/biores.12.2.4410-4477

Hughes, A., and Sullivan, M. (2016). "Targeted cleaning of works on paper: rigid polysaccharide gels and conductivity in aqueous solutions," The Book and Paper Group Annual 25, 30-41.

Ishida, T., Mitarai, M., Sugano, Y., and Shoda, M. (2003). "Role of water-soluble polysaccharides in bacterial cellulose production," Biotechnology and Bioengineering 83(4), 474-478. DOI: 10.1002/bit.10690.

ISO 5630-4 (1986). "Paper and board - Accelerated aging - Part 4: Dry heat treatment at 120 or $150{ }^{\circ} \mathrm{C}$," International Organization for Standardization, Geneva, Switzerland.

ISO 6588-1 (2005). "Paper, board and pulps — Determination of pH of aqueous extracts

- Part 1: Cold extraction," International Organization for Standardization, Geneva, Switzerland, 2005. 
Jönsson, M., Allahgholi, L., Sardari, R. R., Hreggviðsson, G. O., and Nordberg Karlsson, E. (2020). "Extraction and modification of macroalgal polysaccharides for current and next-generation applications," Molecules 25(4), 930. DOI: 10.3390/molecules25040930

Kelly, G. B. (1987). "Non-aqueous deacidification of books and paper," in: The Conservation of Library and Archive Materials and the Graphic Arts, G. Petherbridge (ed.), Butterworths, London, England, pp. 117-123.

Khandekar, N. (2000). "A survey of the conservation literature relating to the development of aqueous gel cleaning on painted and varnished surfaces," Studies in Conservation 45(1), 10-20. DOI: 10.1179/sic.2000.45.s3.003

Kolar, J. (1997). "Mechanism of autoxidative degradation of cellulose," Restaurator. International Journal for the Preservation of Library and Archival Material 18(4), 163-176. DOI: 10.1515/rest.1997.18.4.163

Kolar, J., Strlic, M., Budnar, M., Malesic, J., Selih, V. S., and Simcic, J. (2003). "Stabilisation of corrosive iron gall inks," Acta Chimica Slovenica 50(4), 763-770.

Kolar, J., Stolfa, A., Strlic, M., Pompe, M., Pihlar, B., and Budnar, M. (2006). "Historical iron gall ink containing documents: Properties affecting their condition," Analytica Chimica Acta 555(1), 167-174. DOI: 10.1016/j.aca.2005.08.073

Kočar, D., Strlič, M., Kolar, J., and Pihlar, B. (2004). "Determination of pH of paper," in: Proceedings of the International Conference Durability of Paper and Writing, J. Kolar, M. Strlic, and J. B. G. A. Havermans (eds.), National and University Library, Ljubljana, Slovenia, pp. 26-27.

Mohamed, W. A., Mansour, M. M. A., and Salem, M. Z. M. (2019). "Lemna gibba and Eichhornia crassipes extracts: Clean alternatives for deacidification, antioxidation and fungicidal treatment of historical paper," Journal of Cleaner Production 219, 846-855. DOI: 10.1016/j.jclepro.2019.02.097

Olabi, A. G. (2017). "Renewable energy and energy storage systems," Energy 136, 1-6. DOI: 10.1016/j.energy.2017.07.054

Poggi, G., Giorgi, R., Toccafondi, N., Katzur, V., and Baglioni, P. (2010). "Hydroxide nanoparticles for deacidification and concomitant inhibition of iron-gall ink corrosion of paper," Langmuir 26(24), 19084-19090. DOI: 10.1021/la1030944

Riedo, C., Caldera, F., Poli, T., and Chiantore, O. (2015). "Poly (vinylalcohol)-borate hydrogels with improved features for the cleaning of cultural heritage surfaces," Heritage Science 3(1), 23. DOI: 10.1186/s40494-015-0053-2

Sacco, P., Furlani, F., De Marzo, G., Marsich, E., Paoletti, S., and Donati, I. (2018). "Concepts for developing physical gels of chitosan and of chitosan derivatives," Gels 4(3), p.67. DOI: 10.3390/gels4030067

Salem, M. Z. M., Hamed, S. A. E. K. M., and Mansour, M. M. A. (2019). "Assessment of efficacy and effectiveness of some extracted bio-chemicals as bio-fungicides on wood," Drvna Industrija 70(4), 337-350. DOI: 10.5552/drvind.2019.1837

TAPPI 509 om-02 (2002). "Hydrogen ion concentration $(\mathrm{pH})$ of paper extracts (hot extraction method) (Reaffirmation of T 435 om-02)," TAPPI Press, Atlanta, GA, USA.

TAPPI 402 sp-08 (2013). "Standard conditioning and testing atmospheres for paper, board, pulp handsheets, and related products," TAPPI Press, Atlanta, GA, USA.

Wahba, W. N., Salim, E., and Hassan, R. R. A. (2020). "A microscopic examination to monitor the historical paper dyeing techniques," Scientific Culture 6(2), 1-10. DOI: 10.5281/zenodo.3724838 
Warda, J., Brückle, I., Bezúr, A., and Kushel, D. (2007). "Analysis of agarose, carbopol, and laponite gel poultices in paper conservation," Journal of the American Institute for Conservation 46(3), 263-279. DOI: 10.1179/019713607806112260

Zarubica, A. R., Miljković, M. N., Purenović, M. M., and Tomić, V. B. (2005). “Colour parameters, whiteness indices and physical features of marking paints for horizontal signalization," Facta Universitatis-Series: Physics, Chemistry and Technology 3(2), 205-216.

Zou, X., Uesaka, T., and Gurnagul, N. (1996). "Prediction of paper permanence by accelerated aging II. Comparison of the predictions with natural aging results," Cellulose 3(1), 269-279. DOI: 10.1007/BF02228806

Article submitted: May 11, 2020; Peer review completed: June 28, 2020; Revised version received and accepted: July 3, 2020; Published: July 9, 2020.

DOI: 10.15376/biores.15.3.6576-6599 